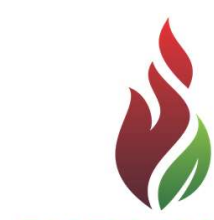

SUSTENERE

Publishing Corporation

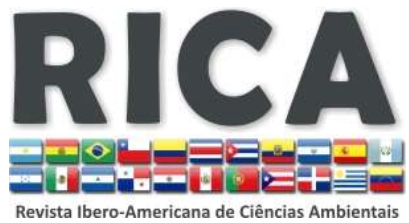

Journals Homepage:

www.sustenere.co/journals

\section{MODELO CONCEITUAL DO SISTEMA LOGÍSTICO REVERSO DO RESÍDUO SÓLIDO URBANO}

\section{RESUMO}

A logística reversa do resíduo sólido urbano vem recebendo importância ao longo dos últimos anos devido ao aumento da geração de resíduos em países em desenvolvimento e da necessidade de estruturação neste setor. Estruturas e resultados diversos da gestão de resíduos podem ser observados mundo a fora Este artigo analisa as características da estruturação deste sistema através da revisão bibliográfica narrativa. Foi observado que mesmo as estruturas sendo diversas, existem semelhanças nas suas atividades e características, possibilitando o desenvolvimento do modelo conceitual do sistema logístico reverso do resíduo sólido urbano como conclusão deste artigo.

PALAVRAS-CHAVES: Logística Reversa; Gestão de Resíduo; Resíduo Sólido Urbano e Revisão Bbibliográfica Narrativa.

\section{CONCEPTUAL MODEL OF REVERSE LOGISTICS SYSTEM OF MUNICIPAL SOLID WASTE}

\section{ABSTRACT}

The reverse logistics of municipal solid waste is receiving importance over the last years due to increased waste generation in developing countries and the need for structuring this sector. Several structures and results of waste management can be observed around the world. This paper analyzes the features of this system structure through the narrative literature review. It has been observed that even structures being different, there are similarities in their activities and characteristics, enabling the development of the conceptual model of reverse logistics system of municipal solid waste as a conclusion of this article.

KEYWORDS: Reverse Logistics; Waste Management; Municipal Solid Waste and Narrative Literature Review.
Revista Ibero-Americana de

Ciências Ambientais, Aquidabã, v.6, n.2, Jun, Jul, Ago, Set, Out, Nov 2015.

ISSN 2179-6858

\section{SECTION: Articles}

TOPIC: Gestão Ambiental

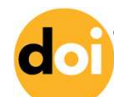

DOI: 10.6008/SPC2179-6858.2015.002.0008

Yuka Akasaka

Universidade Federal do Rio de Janeiro, Brasil http://lattes.cnpq.br/1775286579503270 vuka.akasaka@gmail.com

Márcio de Almeida D'Agosto Universidade Federal do Rio de Janeiro, Brasil http://lattes.cnpq.br/8875361042998659 dagosto@pet.coppe.ufri.br

Received: $17 / 03 / 2015$

Approved: 14/10/2015

Reviewed anonymously in the process of blind peer.

Referencing this:

AKASAKA, Y.; D'AGOSTO, M. A.. Modelo conceitual do sistema logístico reverso do resíduo sólido urbano. Revista Ibero-Americana de Ciências Ambientais, Aquidabã, v.6, n.2, p.101-120, 2015. DOI: http://dx.doi.org/10.6008/SPC2179$\underline{6858.2015 .002 .0008}$ 


\section{INTRODUÇÃO}

O resíduo sólido urbano (RSU) tem características variadas em função de aspectos sociais, econômicos, culturais, geográficos e climáticos. A estruturação do sistema para a gestão do RSU é diferente em cada país devido às características da sua geração e pela legislação de melhoria da saúde pública e ao direcionamento sócio-político deste setor. Nos EUA foram gerados em 2011 cerca de 250 milhões de toneladas de resíduos, sendo que $26 \%$ foram reciclados, 8,7\% compostados, $11,6 \%$ conduzidos para combustão com recuperação energética e 53,8\% descartados em aterros sanitários (EPA, 2011). Na Europa, em 2012, a geração de resíduo dos 27 países que compõem a União Europeia foi de 244 milhões de toneladas, nos quais $27 \%$ foram reciclados, $14,7 \%$ compostados, $23,7 \%$ encaminhados para combustão com valorização energética e 34,4\% descartados em aterros sanitários (EUROSTAT, 2014).

Já na China, em 2006, a geração estimada de RSU foi de aproximadamente de 212 milhões de toneladas, no entanto apenas 148 milhões de toneladas foram coletados e transportados. Deste montante $6,4 \%$ foram incinerados, $2,2 \%$ passaram por compostagem e cerca de $91,4 \%$ dos resíduos foram para os aterros sanitários. Aproximadamente 64 milhões de toneladas, 30\% dos resíduos gerados, não foram controlados (Zhang et al., 2010).

No Brasil, de acordo com ABRELPE (2013), foi estimada a geração de resíduos para o ano de 2013 em 209 toneladas ao dia, ou seja, 76 milhões de toneladas ao ano. Destes foram coletados cerca de 69 milhões de toneladas, porém não foi possível encontrar um panorama geral da gestão do RSU por tipo de processamento. Além disso, cerca de 28,8 milhões de toneladas de resíduos coletados foram destinados em locais inadequados, como aterros controlados e lixões. Percebe-se uma grande diferença de resultado da gestão do RSU nos EUA e nos países da União Europeia em relação ao Brasil e China. Isto é devido não apenas à composição gravimétrica, mas também ao histórico de desenvolvimento da gestão do RSU em cada país. Em comparação com os países desenvolvidos, a estruturação deste tema nos países em desenvolvimento se iniciou recentemente.

Vale ressaltar que mesmo entre os países desenvolvidos há uma considerável diferença entre os resultados, onde a União Europeia, em comparação com os EUA, apresenta quase $70 \%$ a mais de RSU sendo compostados e mais que o dobro passando por valorização energética. Tais diferenças nos resultados derivam das diferentes formas de estruturação do sistema logístico reverso do RSU. Dessa forma, este artigo tem como objetivo analisar e caracterizar este processo, com o intuito de estruturar um modelo conceitual do sistema logístico reverso do RSU, como contribuição principal deste estudo. Para tanto, esta estruturação considera uma abordagem diferenciada, que procura integrar os conceitos de logística reversa e gestão de resíduos sólidos, representando outra contribuição inovadora deste trabalho.

A metodologia utilizada neste trabalho consiste na revisão bibliográfica narrativa, que levou em consideração duas tipologias de fontes de consulta: artigos acadêmicos e diretrizes e guias de 
implantação do gerenciamento integrado do RSU. A partir desta introdução, este artigo se divide em 5 seções. A segunda seção apresenta a revisão teórica do conceito da logística reversa do RSU. As seções 3 e 4 apresentam a metodologia de pesquisa e o resultado do estudo, respectivamente. Na seção 5 apresenta a discussão do resultado e a contribuição principal deste trabalho. Por fim, a seção 6 apresenta a conclusão e as considerações finais deste trabalho.

\section{REVISÃO TEÓRICA}

Nesta seção apresenta-se o conceito da logística reversa do RSU, que é apresentado e analisado na literatura acadêmica em dois campos de estudo, o da logística reversa e o da gestão de resíduos. Estes dois campos de estudo vêm recebendo atenção progressiva nos últimos anos e desenvolvem-se de forma paralela na literatura. Este processo fez com que, apesar dos assuntos serem convergentes, sua abordagem apresenta a falta de integração e sintetização dos conceitos, sendo possível encontrar muitas vezes termologias diversas com o mesmo significado.

$\mathrm{Na}$ logística reversa, independente do produto ou resíduo, observa-se quatro atividades que fazem parte de qualquer sistema: coleta, inspeção, triagem e destinação. A coleta refere-se às atividades de movimentação para consolidação do produto/resíduo para inserção no sistema logístico reverso. A inspeção é a verificação da qualidade e/ou característica do produto/resíduo. Após esses processos, o produto/resíduo podem ser triados e destinados adequadamente para os métodos de valorização conveniente (ROGERS \& TIBBEN-LEMBKE, 1998; BRITO \& DEKKER, 2003; FLEISCHMANN et al., 2000).

Os métodos de valorização são inúmeros. Caso o produto/resíduo esteja com uma boa qualidade sem necessidade de reparo, podem ser inseridos quase que imediatamente no mercado na forma de revenda/reuso, venda com desconto e redistribuição. Nos casos em que esteja com problemas de qualidade, é necessário passar por um reprocessamento, que pode ser em níveis variados, conforme definição de Thierry et al. (1995): nível do produto (reparo), nível de módulos (remodelagem), nível de componente (remanufatura), nível de peça parte (recuperação), nível de material (reciclagem) e nível energético (incineração). Nos casos em que não há mais possibilidade de valorização, estes são encaminhados para o descarte, usualmente nos aterros sanitários (BRITO \& DEKKER, 2003; ROGERS \& TIBBEN-LEMBKE, 1998; MCKINNON et al., 2010; THIERRY et al., 1995).

Já na gestão de resíduos estuda-se o tema estruturando-o em 4 atividades: coleta, transporte, processamento e disposição (EPA, 1974). Complementando esta definição, foi estabelecido em 1989, nos EUA pela EPA (Environmental Protection Agency), o conceito da gestão integrada dos resíduos, que define uma hierarquia do processo de valorização que se constitui em quatro níveis: redução/reuso, reciclagem/compostagem, combustão com recuperação energética e descarte. 
Na Europa, a hierarquização utilizada para a gestão integrada é composta por 5 níveis: prevenção/redução, reuso, reciclagem, outros meios de recuperação e descarte (EC, 2010). Já no Brasil, a Política Nacional de Resíduos Sólidos (PNRS) estabelece que na gestão do resíduo sólido, deva-se seguir a seguinte ordem de prioridade: não geração, redução, reutilização, reciclagem, tratamento dos resíduos sólidos e disposição final ambientalmente adequada dos rejeitos.

Dessa forma, percebe-se que assim como na logística reversa, a gestão de resíduos mostra uma estrutura de atividades e hierarquização dos métodos de valorização do resíduo. Os métodos de valorização da logística reversa e a hierarquização da gestão integrada do resíduo sólido (GIRS) podem ser comparados na Tabela 1, onde percebe-se semelhanças na abordagem nos dois campos de estudos. Observa-se que os métodos de valorização de reparo, remodelagem, remanufatura e recuperação que se apresentam da logística reversa não são compatíveis com nenhum nível na GIRS. Isso se deve ao motivo da logística reversa se estruturar tanto no sistema pós-venda, com a movimentação de produtos, quanto no sistema de pósconsumo, com a movimentação de resíduos. Já a gestão de resíduos apenas movimenta resíduos no sistema de pós-consumo, portanto, os métodos de valorização que se referem ao produto não se encaixam na hierarquização da GIRS.

Tabela 1: Comparação dos Métodos de Valorização da Logística Reversa com a Hierarquização da GIRS.

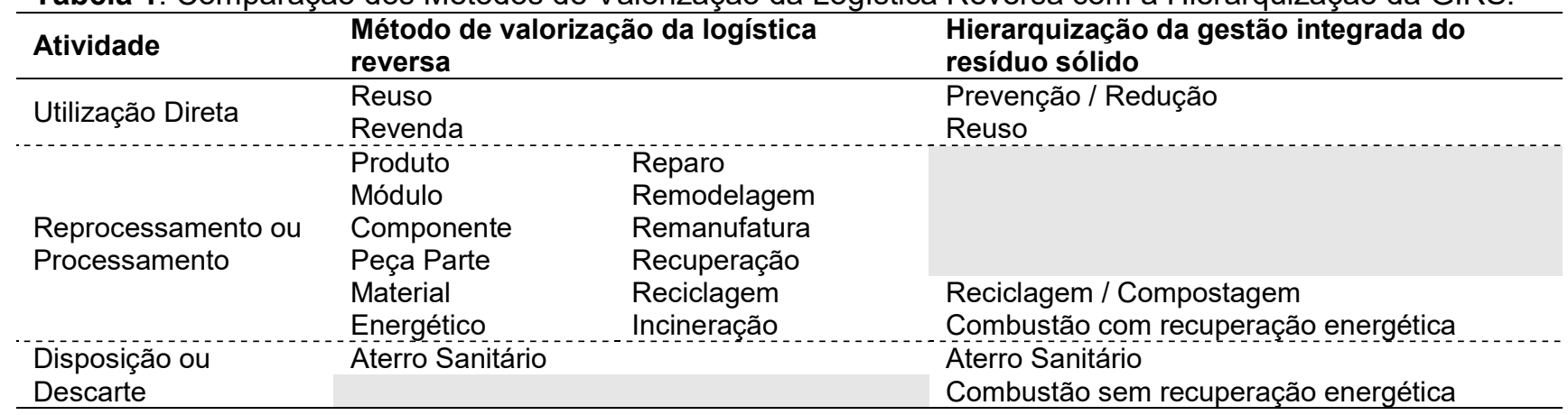

Ainda observa-se na Tabela 1 que a gestão de resíduos considera a combustão sem a valorização energética com o objetivo de descarte do resíduo com uma granulometria menor. Na logística reversa, no entanto, já que se caracteriza pelo objetivo de valorização do produto/resíduo, a combustão de resíduos deve ser considerada apenas para a recuperação e valorização energética na forma de reprocessamento.

As atividades da logística reversa e da gestão de resíduos também são semelhantes. Sendo que as atividades da logística reversa (coleta, inspeção, triagem e destinação) e da gestão de resíduos (coleta, transporte, processamento e disposição) são coincidentes em ambos os campos de estudo. A atividade de processamento, da gestão de resíduos, apresenta-se como reprocessamento, na logística reversa, e a atividade de disposição como descarte, além da atividade de transporte que interliga todo processo de movimentação do produto/resíduo. Para a 
conceitualização da logística reversa do resíduo sólido, neste trabalho, utilizam-se as nomenclaturas 'processamento' e 'descarte'.

Além disso, a atividade da coleta, na logística reversa, é o processo no qual se inclui a atividade de transporte até a localidade da atividade de inspeção. Já na gestão de resíduos, a atividade de coleta é definida apenas como remoção do resíduo, definindo o processo de movimentação para a próxima localidade, como a atividade de transporte. Já a atividade de inspeção, na logística reversa do resíduo sólido ocorre antes da atividade de coleta e com o intuito de utilização direta do resíduo (prevenção, redução e reuso). Após esgotada esta possibilidade, o resíduo precisa passar por algum método de valorização para ser reutilizado no mercado, iniciando este processo pela atividade de coleta.

A atividade de descarte que na gestão de resíduos apresenta-se como o último nível da hierarquização, na Figura 1, apresenta-se como um processo a parte, como na logística reversa. Pois se define como uma destinação final do resíduo, não sendo possível voltar ao mercado consumidor como acontecem nos demais níveis da pirâmide. Ainda, todos os métodos de valorização apresentados na atividade de processamento geram rejeitos no processo em que devem ser encaminhados para descarte. Na Figura 1 é apresentado o processo logístico reverso do resíduo sólido urbano, procurando integrar a estrutura da logística reversa apresentada por De Brito e Dekker (2003) e da gestão de resíduos apresentados por EC (2010) e Abrelpe e ISWA (2013).

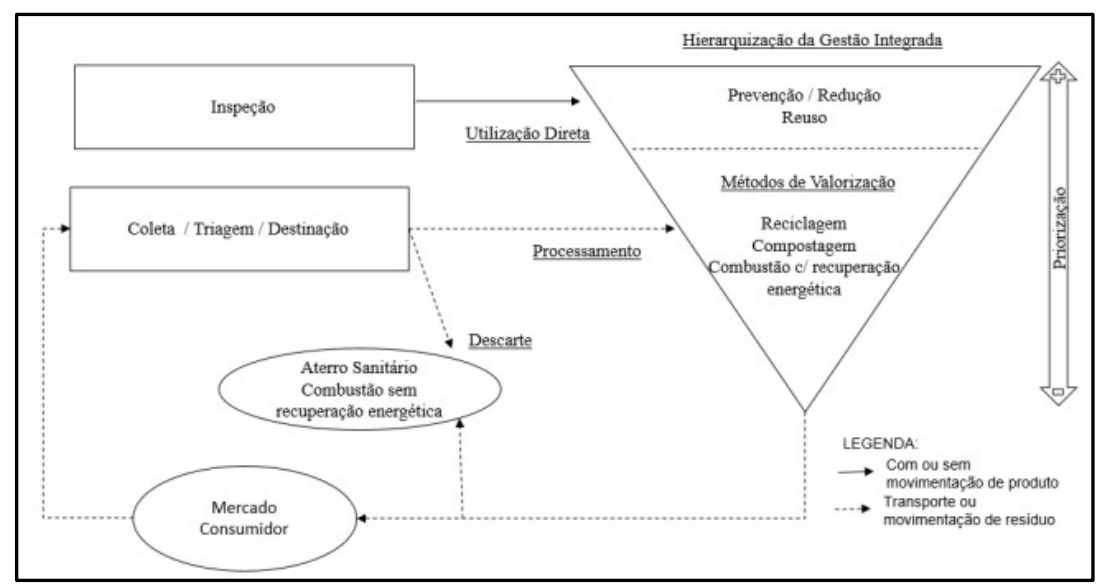

Figura 1: Processos da Logística Reversa do Resíduo Sólido Urbano.

Fonte: De Brito e Dekker, 2003; EC, 2010; Abrelpe e ISWA, 2013.

A partir do estabelecimento do conceito da logística reversa do resíduo sólido urbano, avalia-se e caracteriza-se o sistema logístico reverso do resíduo sólido urbano, levando em consideração a estrutura de atividades e hierarquização dos métodos de valorização.

\section{METODOLOGIA}

Para estruturar um modelo conceitual dos sistemas logístico reversos do RSU, através da revisão bibliográfica narrativa, selecionaram-se artigos que estruturassem e/ou descrevessem o 
sistema logístico reverso do RSU no Brasil, Estados Unidos, Canadá, México, União Europeia, China e Índia. Os estudos foram selecionados em função da sua data de publicação, considerando os últimos 10 anos. Ao mesmo tempo, foram selecionadas diretrizes e guias de implantação da gestão dos resíduos sólidos urbanos no Brasil, Estados Unidos e União Europeia. Não foi possível encontrar as diretrizes de implantação do Canadá, México, Índia e China.

Os artigos acadêmicos pesquisados são sintetizados na Tabela 2, descrevendo o sistema logístico reverso do RSU de cada estudo, estruturando-os pelas atividades apresentadas e classificando-os quando possível. As atividades detalhadas são a coleta, triagem, destinação, transporte, processamento e descarte. A atividade de processamento subdivide-se em três métodos de valorização, a reciclagem, compostagem e combustão com recuperação energética. $E$ a atividade de descarte é representada pelo aterro sanitário.

Dos 43 artigos analisados, $75 \%$ apresentam a utilização de uma planta intermediária no sistema. Devido à relevância deste tópico, também se descreve na Tabela 2 a presença da planta intermediária no sistema, detalhando o tipo e as atividades que são executadas. Este assunto será abordado com mais detalhes junto às atividades do sistema logístico reverso do RSU na próxima seção deste artigo. As diretrizes e guias de implantação da gestão dos resíduos sólidos urbanos foram utilizados para análise de cada atividade da logística reversa do RSU com o intuito de dar consistência ao resultado obtido na tabulação dos artigos.

Tabela 2: Classificação das Atividades do Sistema Logístico Reverso do RSU.

\begin{tabular}{|c|c|c|c|c|c|c|c|c|c|c|c|}
\hline \multirow[t]{2}{*}{ Pais } & \multirow{2}{*}{$\begin{array}{l}\text { Referência } \\
\text { Bibliográfica }\end{array}$} & \multirow[t]{2}{*}{ Coleta } & \multirow[t]{2}{*}{ Triagem } & \multirow[t]{2}{*}{ Destinação } & \multirow[t]{2}{*}{ Transporte } & \multicolumn{3}{|c|}{ Processamento } & \multirow{2}{*}{$\begin{array}{l}\text { Descarte } \\
\text { Aterro } \\
\text { Sanitário }\end{array}$} & \multicolumn{2}{|c|}{ Planta Intermediária } \\
\hline & & & & & & REC & COMP & CCRE & & Tipo & Atividade \\
\hline Chin a & Hui et al., 2006 & $\begin{array}{l}\text { Coleta } \\
\text { indiferen } \\
\text { ciada } \\
\text { com } \\
\text { ponto de } \\
\text { entrega }\end{array}$ & $\begin{array}{l}\text { - SF: } \\
\text { estação de } \\
\text { transferência } \\
\text { - SI: no } \\
\text { ponto de } \\
\text { entrega, } \\
\text { exclusivame } \\
\text { nte para } \\
\text { resíduos } \\
\text { recicláveis }\end{array}$ & $\begin{array}{l}\text { - SF: estação de } \\
\text { transferência } \\
\text { - SI: no ponto de } \\
\text { entrega, } \\
\text { exclusivamente } \\
\text { para resíduos } \\
\text { recicláveis }\end{array}$ & Coleta e TRANSF & $\mathrm{x}$ & - & $x$ & $\begin{array}{l}\text { Aterro } \\
\text { sanitário e } \\
\text { aterro } \\
\text { controlado }\end{array}$ & $\begin{array}{l}\text { Estação } \\
\text { de } \\
\text { TRANSF }\end{array}$ & $\begin{array}{l}\text { Triagem e } \\
\text { destinação }\end{array}$ \\
\hline Portugal & $\begin{array}{l}\text { Semiao et al., } \\
2006\end{array}$ & $\begin{array}{l}\text { Coleta } \\
\text { seletiva } \\
\text { com } \\
\text { ponto de } \\
\text { entrega } \\
\text { voluntári } \\
\text { a } \\
\end{array}$ & $\begin{array}{l}\text { Geração e } \\
\text { centro de } \\
\text { triagem }\end{array}$ & $\begin{array}{l}\text { Geração e centro } \\
\text { de triagem }\end{array}$ & Coleta e TRANSF & $\mathrm{x}$ & $\mathrm{x}$ & $x$ & $\begin{array}{l}\text { Aterro } \\
\text { sanitário }\end{array}$ & $\begin{array}{l}\text { Centro de } \\
\text { triagem }\end{array}$ & $\begin{array}{l}\text { Triagem e } \\
\text { destinação }\end{array}$ \\
\hline China & $\begin{array}{l}\text { Hong-tao et al., } \\
2007\end{array}$ & $\begin{array}{l}\text { Coleta } \\
\text { seletiva }\end{array}$ & $\begin{array}{l}\text { Geração e } \\
\text { estação de } \\
\text { transferência }\end{array}$ & $\begin{array}{l}\text { Geração e estação } \\
\text { de transferência }\end{array}$ & TRANSF & $\mathrm{x}$ & $x$ & $x$ & $\begin{array}{l}\text { Aterro } \\
\text { sanitário c/ } \\
\text { e s/RE }\end{array}$ & $\begin{array}{l}\text { Estação } \\
\text { de } \\
\text { TRANSF }\end{array}$ & $\begin{array}{l}\text { Triagem e } \\
\text { destinação }\end{array}$ \\
\hline Canadá & Yeomans, 2007 & $\begin{array}{l}\text { Coleta } \\
\text { seletiva } \\
\text { com } \\
\text { ponto de } \\
\text { entrega } \\
\text { voluntári } \\
\text { a } \\
\end{array}$ & $\begin{array}{l}\text { Geração e } \\
\text { estação de } \\
\text { transferência }\end{array}$ & $\begin{array}{l}\text { Geração e estação } \\
\text { de transferência }\end{array}$ & Coleta e TRANSF & $x$ & - & $x$ & $\begin{array}{l}\text { Aterro } \\
\text { sanitário }\end{array}$ & $\begin{array}{l}\text { Estação } \\
\text { de } \\
\text { TRANSF }\end{array}$ & $\begin{array}{l}\text { Compactação, } \\
\text { triagem e } \\
\text { destinação }\end{array}$ \\
\hline \multirow[t]{2}{*}{ Grécia } & \multirow[t]{2}{*}{$\begin{array}{l}\text { Erkut et al., } \\
2008\end{array}$} & \multirow[t]{2}{*}{$\begin{array}{l}\text { Coleta } \\
\text { seletiva }\end{array}$} & \multirow[t]{2}{*}{$\begin{array}{l}\text { Geração e } \\
\text { estação de } \\
\text { transferência }\end{array}$} & \multirow[t]{2}{*}{$\begin{array}{l}\text { Geração e estação } \\
\text { de transferência }\end{array}$} & \multirow[t]{2}{*}{ Coleta e TRANSF } & \multirow[t]{2}{*}{$\mathrm{x}$} & \multirow[t]{2}{*}{$\mathrm{x}$} & \multirow[t]{2}{*}{$\mathrm{x}$} & \multirow[t]{2}{*}{$\begin{array}{l}\text { Aterro } \\
\text { sanitário }\end{array}$} & $\begin{array}{l}\text { Estação } \\
\text { de } \\
\text { TRANSF }\end{array}$ & $\begin{array}{l}\text { Triagem e } \\
\text { destinação }\end{array}$ \\
\hline & & & & & & & & & & $\begin{array}{l}\text { PP do } \\
\text { RDF }\end{array}$ & $\begin{array}{l}\text { Produção do } \\
\text { RDF }\end{array}$ \\
\hline Canadá & Li et al., 2008 & $\begin{array}{l}\text { Coleta } \\
\text { seletiva }\end{array}$ & Geração & Geração & Coleta e TRANSF & $x$ & $x$ & - & $\begin{array}{l}\text { Aterro } \\
\text { sanitário }\end{array}$ & - & - \\
\hline China & Su et al., 2008 & Coleta & Estação de & Estação de & TRANSF & $\mathrm{x}$ & $\mathrm{x}$ & $\mathrm{x}$ & Aterro & Estação & Triagem e \\
\hline
\end{tabular}




\begin{tabular}{|c|c|c|c|c|c|c|c|c|c|c|c|}
\hline & & $\begin{array}{l}\text { indiferen } \\
\text { ciada }\end{array}$ & transferência & transferência & & & & & sanitário & $\begin{array}{l}\text { de } \\
\text { TRANSF }\end{array}$ & destinação \\
\hline Itália & $\begin{array}{l}\text { Messineo e } \\
\text { Panno, } 2008\end{array}$ & $\begin{array}{l}\text { Coleta } \\
\text { seletiva }\end{array}$ & $\begin{array}{l}\text { Geração e } \\
\text { centro de } \\
\text { triagem }\end{array}$ & $\begin{array}{l}\text { Geração e centro } \\
\text { de triagem }\end{array}$ & Coleta e TRANSF & $\mathrm{x}$ & $x$ & $\mathrm{x}$ & $\begin{array}{l}\text { Aterro } \\
\text { sanitário }\end{array}$ & $\begin{array}{l}\text { Centro de } \\
\text { triagem }\end{array}$ & $\begin{array}{l}\text { Triagem e } \\
\text { destinação }\end{array}$ \\
\hline \multirow[t]{2}{*}{ Itália } & \multirow[t]{2}{*}{$\begin{array}{l}\text { Robba et al., } \\
2008\end{array}$} & \multirow[t]{2}{*}{$\begin{array}{l}\text { Coleta } \\
\text { seletiva }\end{array}$} & \multirow{2}{*}{$\begin{array}{l}\text { Geração e } \\
\text { centro de } \\
\text { triagem }\end{array}$} & \multirow[t]{2}{*}{$\begin{array}{l}\text { Geração e centro } \\
\text { de triagem }\end{array}$} & \multirow[t]{2}{*}{ TRANSF } & \multirow[t]{2}{*}{$x$} & \multirow[t]{2}{*}{$\mathrm{x}$} & \multirow[t]{2}{*}{$x$} & \multirow[t]{2}{*}{$\begin{array}{l}\text { Aterro } \\
\text { sanitário }\end{array}$} & $\begin{array}{l}\text { Centro de } \\
\text { triagem }\end{array}$ & $\begin{array}{l}\text { Triagem e } \\
\text { destinação }\end{array}$ \\
\hline & & & & & & & & & & $\begin{array}{l}\text { PP do } \\
\text { RDF }\end{array}$ & $\begin{array}{l}\text { Produção do } \\
\text { RDF }\end{array}$ \\
\hline Itália & $\begin{array}{l}\text { Feo e Malvano, } \\
2009\end{array}$ & $\begin{array}{l}\text { Coleta } \\
\text { seletiva }\end{array}$ & Geração & Geração & TRANSF & $x$ & $x$ & $x$ & $\begin{array}{l}\text { Aterro } \\
\text { sanitário }\end{array}$ & $\begin{array}{l}\text { PP do } \\
\text { RDF }\end{array}$ & $\begin{array}{l}\text { Processo de } \\
\text { TMB }\end{array}$ \\
\hline
\end{tabular}

Tabela 2 Continuação: Classificação das Atividades do Sistema Logístico Reverso do RSU.

\begin{tabular}{|c|c|c|c|c|c|c|c|c|c|c|c|}
\hline \multirow[t]{2}{*}{ País } & \multirow{2}{*}{$\begin{array}{l}\text { Referênci } \\
\text { a }\end{array}$} & \multirow[t]{2}{*}{ Coleta } & \multirow[t]{2}{*}{ Triagem } & \multirow{2}{*}{$\begin{array}{l}\text { Destinaçã } \\
\text { o }\end{array}$} & \multirow[t]{2}{*}{ Transporte } & \multicolumn{3}{|c|}{ Processamento } & \multirow{2}{*}{$\begin{array}{l}\text { Descarte } \\
\text { Aterro } \\
\text { Sanitário }\end{array}$} & \multicolumn{2}{|c|}{ Planta Intermediária } \\
\hline & & & & & & REC & COMP & $\begin{array}{l}\text { CCR } \\
\text { E }\end{array}$ & & Tipo & Atividade \\
\hline İndia & $\begin{array}{l}\text { Talyan et } \\
\text { al., } 2008\end{array}$ & $\begin{array}{l}\text { Coleta } \\
\text { seletiva } \\
\text { porta-a- } \\
\text { porta } \\
\text { com } \\
\text { carrinh } \\
\text { o de } \\
\text { mão } \\
\text { até o } \\
\text { ponto } \\
\text { de } \\
\text { entrega }\end{array}$ & $\begin{array}{l}\text { - SF: geração } \\
\text { - Sl: na coleta, } \\
\text { ponto de } \\
\text { entrega e lixão, } \\
\text { exclusivamente } \\
\text { para resíduos } \\
\text { recicláveis }\end{array}$ & $\begin{array}{l}\text { - SF: } \\
\text { ponto de } \\
\text { entrega } \\
\text { - Sl: na } \\
\text { coleta, } \\
\text { ponto de } \\
\text { entrega e } \\
\text { Lixão, } \\
\text { exclusiva } \\
\text { mente } \\
\text { para } \\
\text { resíduos } \\
\text { recicláveis }\end{array}$ & $\begin{array}{l}\text { Coleta e } \\
\text { TRANSF * }\end{array}$ & $x$ & $x$ & - & Lixão & - & - \\
\hline \multirow[t]{2}{*}{ Canadá } & \multirow[t]{2}{*}{$\begin{array}{l}\text { Warith et } \\
\text { al., } 2008\end{array}$} & \multirow{2}{*}{$\begin{array}{l}\text { Coleta } \\
\text { seletiva } \\
\text { com } \\
\text { ponto } \\
\text { de } \\
\text { entrega } \\
\text { voluntá } \\
\text { ria }\end{array}$} & \multirow[t]{2}{*}{$\begin{array}{l}\text { Geração, centro } \\
\text { de triagem e } \\
\text { estação de } \\
\text { transferência }\end{array}$} & \multirow{2}{*}{$\begin{array}{l}\text { Geração, } \\
\text { centro de } \\
\text { triagem e } \\
\text { estação } \\
\text { de } \\
\text { transferên } \\
\text { cia }\end{array}$} & \multirow[t]{2}{*}{$\begin{array}{l}\text { Coleta e } \\
\text { TRANSF }\end{array}$} & \multirow[t]{2}{*}{$x$} & \multirow[t]{2}{*}{$x$} & \multirow[t]{2}{*}{-} & \multirow[t]{2}{*}{$\begin{array}{l}\text { Aterro } \\
\text { sanitário }\end{array}$} & $\begin{array}{l}\text { Centro } \\
\text { de } \\
\text { triagem }\end{array}$ & $\begin{array}{l}\text { Triagem e } \\
\text { destinação } \\
\text { de } \\
\text { reciclável }\end{array}$ \\
\hline & & & & & & & & & & $\begin{array}{l}\text { Estaçã } \\
\text { o de } \\
\text { TRANS } \\
\text { F } \\
\end{array}$ & $\begin{array}{l}\text { Triagem e } \\
\text { destinação }\end{array}$ \\
\hline Índia & $\begin{array}{l}\text { Dutta et } \\
\text { al., } 2009\end{array}$ & $\begin{array}{l}\text { Coleta } \\
\text { indifere } \\
\text { nciada } \\
\text { porta-a- } \\
\text { porta } \\
\text { com } \\
\text { carrinh } \\
\text { o de } \\
\text { mão } \\
\text { até o } \\
\text { ponto } \\
\text { de } \\
\text { entrega }\end{array}$ & $\begin{array}{l}\text { SI: na coleta e } \\
\text { ponto de } \\
\text { entrega, } \\
\text { exclusivamente } \\
\text { para resíduos } \\
\text { recicláveis }\end{array}$ & $\begin{array}{l}\text { SI: na } \\
\text { coleta e } \\
\text { ponto de } \\
\text { entrega, } \\
\text { exclusiva } \\
\text { mente } \\
\text { para } \\
\text { resíduos } \\
\text { recicláveis }\end{array}$ & $\begin{array}{l}\text { Coleta e } \\
\text { TRANSF }\end{array}$ & $x$ & & & Lixão & - & - \\
\hline China & $\begin{array}{l}\text { Huang et } \\
\text { al., } \\
2009 \text { a }\end{array}$ & $\begin{array}{l}\text { Coleta } \\
\text { indifere } \\
\text { nciada }\end{array}$ & - & - & TRANSF & - & - & $x$ & $\begin{array}{l}\text { Aterro } \\
\text { sanitário }\end{array}$ & - & - \\
\hline China & $\begin{array}{l}\text { Huang et } \\
\text { al., } \\
2009 \text { b }\end{array}$ & $\begin{array}{l}\text { Coleta } \\
\text { indifere } \\
\text { nciada }\end{array}$ & $\begin{array}{l}\text { Estação de } \\
\text { transferência }\end{array}$ & $\begin{array}{l}\text { Estação } \\
\text { de } \\
\text { transferên } \\
\text { cia }\end{array}$ & TRANSF & - & $\mathrm{x}$ & $\mathrm{x}$ & $\begin{array}{l}\text { Aterro } \\
\text { sanitário }\end{array}$ & $\begin{array}{l}\text { Estaçã } \\
\text { o de } \\
\text { TRANS } \\
\text { F }\end{array}$ & $\begin{array}{l}\text { Triagem e } \\
\text { destinação }\end{array}$ \\
\hline China & $\begin{array}{l}\text { Li'ao et } \\
\text { al., } 2009\end{array}$ & $\begin{array}{l}\text { Coleta } \\
\text { indifere } \\
\text { nciada }\end{array}$ & - & - & TRANSF & - & - & - & $\begin{array}{l}\text { Aterro } \\
\text { sanitário }\end{array}$ & $\begin{array}{l}\text { Estaçã } \\
\text { o de } \\
\text { TRANS } \\
\text { F }\end{array}$ & $\begin{array}{l}\text { Consolidaç } \\
\text { ão }\end{array}$ \\
\hline China & $\begin{array}{l}\text { Minghua } \\
\text { et al., } \\
2009\end{array}$ & $\begin{array}{l}\text { Coleta } \\
\text { indifere } \\
\text { nciada }\end{array}$ & $\begin{array}{l}\text { Estação de } \\
\text { transferência }\end{array}$ & $\begin{array}{l}\text { Estação } \\
\text { de } \\
\text { transferên } \\
\text { cia } \\
\end{array}$ & $\begin{array}{l}\text { Coleta e } \\
\text { TRANSF ** }\end{array}$ & - & $x$ & $x$ & $\begin{array}{l}\text { Aterro } \\
\text { sanitário }\end{array}$ & $\begin{array}{l}\text { Estaçã } \\
\text { o de } \\
\text { TRANS } \\
\text { F } \\
\end{array}$ & $\begin{array}{l}\text { Triagem e } \\
\text { destinação }\end{array}$ \\
\hline Itália & $\begin{array}{l}\text { Galante et } \\
\text { al., } 2010\end{array}$ & $\begin{array}{l}\text { Coleta } \\
\text { seletiva }\end{array}$ & Geração & $\begin{array}{l}\text { Estação } \\
\text { de } \\
\text { transferên } \\
\text { cia }\end{array}$ & $\begin{array}{l}\text { Coleta e } \\
\text { TRANSF }\end{array}$ & $x$ & $x$ & $x$ & $\begin{array}{l}\text { Aterro } \\
\text { sanitário }\end{array}$ & $\begin{array}{l}\text { Estaçã } \\
\text { o de } \\
\text { TRANS } \\
\text { F }\end{array}$ & $\begin{array}{l}\text { Consolidaç } \\
\text { ão triagem } \\
\text { e } \\
\text { destinação }\end{array}$ \\
\hline China & $\begin{array}{l}\text { Chen e Li, } \\
2011\end{array}$ & $\begin{array}{l}\text { Coleta } \\
\text { seletiva }\end{array}$ & Geração & Geração & TRANSF & - & $x$ & - & $\begin{array}{l}\text { Aterro } \\
\text { sanitário }\end{array}$ & - & - \\
\hline
\end{tabular}

* Coleta realizada com carrinhos de mão que tem compartimento para resíduos recicláveis e não recicláveis separados.

** Coleta realizada com veículos com equipamentos compactadores e veículos com caçamba basculantes.

Tabela 2 Continuação: Classificação das Atividades do Sistema Logístico Reverso do RSU.

\begin{tabular}{|c|c|c|c|c|c|c|c|c|c|c|c|}
\hline \multirow[t]{2}{*}{ País } & \multirow{2}{*}{$\begin{array}{l}\text { Referência } \\
\text { Bibliográfica }\end{array}$} & \multirow[t]{2}{*}{ Coleta } & \multirow[t]{2}{*}{ Triagem } & \multirow[t]{2}{*}{ Destinação } & \multirow{2}{*}{$\begin{array}{l}\text { Transp } \\
\text { orte }\end{array}$} & \multicolumn{3}{|c|}{ Processamento } & \multirow{2}{*}{ 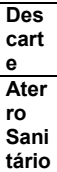 } & \multicolumn{2}{|c|}{ Planta Intermediária } \\
\hline & & & & & & REC & COMP & $\begin{array}{l}\mathrm{CC} \\
\mathrm{RE}\end{array}$ & & Tipo & Atividade \\
\hline \multirow[t]{2}{*}{ China } & \multirow[t]{2}{*}{$\begin{array}{l}\text { Zhen-shan et } \\
\text { al., } 2009\end{array}$} & \multirow[t]{2}{*}{$\begin{array}{l}\text { Coleta } \\
\text { seletiva } \\
\text { porta-a-porta }\end{array}$} & \multirow[t]{2}{*}{$\begin{array}{l}\text { Geraçãa e } \\
\text { estação de } \\
\text { transferência } \\
1\end{array}$} & \multirow[t]{2}{*}{$\begin{array}{l}\text { Geração e estação de } \\
\text { transferência } 1\end{array}$} & \multirow[t]{2}{*}{$\begin{array}{l}\text { TRANS } \\
\mathrm{F}\end{array}$} & \multirow[t]{2}{*}{$x$} & \multirow[t]{2}{*}{$\mathrm{x}$} & \multirow[t]{2}{*}{$\mathrm{x}$} & \multirow[t]{2}{*}{$\begin{array}{l}\text { Aterr } \\
0 \\
\text { sanit } \\
\text { ário }\end{array}$} & $\begin{array}{l}\text { Esta } \\
\text { ção } \\
\text { de } \\
\text { TRA } \\
\text { NSF } \\
1\end{array}$ & $\begin{array}{l}\text { Compactação, } \\
\text { triagem e } \\
\text { destinação }\end{array}$ \\
\hline & & & & & & & & & & $\begin{array}{l}\text { Esta } \\
\text { ção } \\
\text { de } \\
\text { TRA } \\
\text { NSF }\end{array}$ & Compactação \\
\hline
\end{tabular}




\begin{tabular}{|c|c|c|c|c|c|c|c|c|c|c|c|}
\hline & & & & & & & & & & 2 & \\
\hline & & & & & & & & & & $\begin{array}{l}\text { Cent } \\
\text { ro } \\
\text { de } \\
\text { triag } \\
\text { em }\end{array}$ & $\begin{array}{l}\text { Triagem e } \\
\text { destinação de } \\
\text { reciclável }\end{array}$ \\
\hline \multirow[t]{2}{*}{ Espanha } & \multirow[t]{2}{*}{$\begin{array}{l}\text { Bovea et al., } \\
2010\end{array}$} & \multirow[t]{2}{*}{$\begin{array}{l}\text { Coleta } \\
\text { seletiva mista }\end{array}$} & \multirow[t]{2}{*}{$\begin{array}{l}\text { Geração e } \\
\text { centro de } \\
\text { triagem }\end{array}$} & \multirow[t]{2}{*}{$\begin{array}{l}\text { Geração e centro de } \\
\text { triagem }\end{array}$} & \multirow[t]{2}{*}{$\begin{array}{l}\text { Coleta } \\
\text { e } \\
\text { TRANS } \\
\text { F }\end{array}$} & \multirow[t]{2}{*}{$\mathrm{x}$} & \multirow[t]{2}{*}{$x$} & \multirow[t]{2}{*}{-} & \multirow{2}{*}{$\begin{array}{l}\text { Aterr } \\
\text { o } \\
\text { sanit } \\
\text { ário } \\
\text { com } \\
\text { e } \\
\text { sem } \\
\text { RE }\end{array}$} & $\begin{array}{l}\text { Esta } \\
\text { ção } \\
\text { de } \\
\text { TRA } \\
\text { NSF }\end{array}$ & Compactação \\
\hline & & & & & & & & & & $\begin{array}{l}\text { Cent } \\
\text { ro } \\
\text { de } \\
\text { triag } \\
\text { em }\end{array}$ & $\begin{array}{l}\text { Triagem e } \\
\text { destinação }\end{array}$ \\
\hline China & Su et al., 2010 & $\begin{array}{l}\text { Coleta } \\
\text { indiferenciad } \\
\text { a }\end{array}$ & - & - & $\begin{array}{l}\text { TRANS } \\
\mathrm{F}\end{array}$ & - & $x$ & $x$ & $\begin{array}{l}\text { Aterr } \\
\text { o } \\
\text { sanit } \\
\text { ário } \\
\text { com } \\
\mathrm{RE} \\
\end{array}$ & $\begin{array}{l}\text { Esta } \\
\text { ção } \\
\text { de } \\
\text { TRA } \\
\text { NSF }\end{array}$ & $\begin{array}{l}\text { Compactação e } \\
\text { pré-tratamento } \\
\text { para descarte }\end{array}$ \\
\hline China & $\begin{array}{l}\text { Zhang et al., } \\
2010\end{array}$ & $\begin{array}{l}\text { Coleta } \\
\text { indiferenciad } \\
\text { a porta-a- } \\
\text { porta }\end{array}$ & $\begin{array}{l}\text { - SF: Estação } \\
\text { de } \\
\text { transferência } \\
\text { - Sl: na } \\
\text { coleta e } \\
\text { estação de } \\
\text { transferência, } \\
\text { exclusivament } \\
\text { e para } \\
\text { recicláveis }\end{array}$ & $\begin{array}{l}\text { - SF: estação de } \\
\text { transferência } \\
\text { - Sl: na coleta e } \\
\text { estação de } \\
\text { transferência, } \\
\text { exclusivamente para } \\
\text { recicláveis }\end{array}$ & $\begin{array}{l}\text { Coleta } \\
\text { e } \\
\text { TRANS } \\
\text { F }\end{array}$ & $x$ & - & $x$ & $\begin{array}{l}\text { Aterr } \\
\text { o } \\
\text { sanit } \\
\text { ário }\end{array}$ & $\begin{array}{l}\text { Esta } \\
\text { ção } \\
\text { de } \\
\text { TRA } \\
\text { NSF }\end{array}$ & $\begin{array}{l}\text { Triagem e } \\
\text { destinação }\end{array}$ \\
\hline Canadá & $\begin{array}{l}\text { Huang et al. , } \\
2011\end{array}$ & $\begin{array}{l}\text { Coleta } \\
\text { seletiva com } \\
\text { ponto de } \\
\text { entrega } \\
\text { voluntária } \\
\end{array}$ & Geração & $\begin{array}{l}\text { Estação de } \\
\text { transferência }\end{array}$ & $\begin{array}{l}\text { Coleta } \\
\text { e } \\
\text { TRANF } \\
\mathrm{S}\end{array}$ & $x$ & $x$ & $x$ & $\begin{array}{l}\text { Aterr } \\
\text { o } \\
\text { sanit } \\
\text { ário }\end{array}$ & $\begin{array}{l}\text { Esta } \\
\text { ção } \\
\text { de } \\
\text { TRA } \\
\text { NSF }\end{array}$ & $\begin{array}{l}\text { Consolidação e } \\
\text { destinação }\end{array}$ \\
\hline Canadá & $\begin{array}{l}\text { Huang e Zhu, } \\
2011\end{array}$ & $\begin{array}{l}\text { Coleta } \\
\text { seletiva }\end{array}$ & Geração & Geração & $\begin{array}{l}\text { TRANS } \\
\mathrm{F}\end{array}$ & $x$ & $x$ & - & $\begin{array}{l}\text { Aterr } \\
\text { o } \\
\text { sanit } \\
\text { ário }\end{array}$ & - & - \\
\hline China & Li et al., 2011_a & $\begin{array}{l}\text { Coleta } \\
\text { seletiva com } \\
\text { ponto de } \\
\text { entrega } \\
\text { voluntária }\end{array}$ & $\begin{array}{l}\text { SI: na coleta } \\
\text { e estação de } \\
\text { TRANSF, } \\
\text { exclusivament } \\
\text { e para } \\
\text { recicláveis }\end{array}$ & $\begin{array}{l}\text { SI: na coleta e estação } \\
\text { de TRANSF, } \\
\text { exclusivamente para } \\
\text { recicláveis }\end{array}$ & $\begin{array}{l}\text { TRANS } \\
\mathrm{F}\end{array}$ & - & $\mathrm{x}$ & $\mathrm{x}$ & $\begin{array}{l}\text { Aterr } \\
\text { o } \\
\text { sanit } \\
\text { ário }\end{array}$ & $\begin{array}{l}\text { Esta } \\
\text { ção } \\
\text { de } \\
\text { TRA } \\
\text { NSF }\end{array}$ & $\begin{array}{l}\text { Pré-tratamento, } \\
\text { triagem e } \\
\text { destinação }\end{array}$ \\
\hline
\end{tabular}

Tabela 2 - Continuação: Classificação das Atividades do Sistema Logístico Reverso do RSU.

\begin{tabular}{|c|c|c|c|c|c|c|c|c|c|c|c|}
\hline \multirow[t]{2}{*}{ País } & \multirow[t]{2}{*}{$\begin{array}{l}\text { Referência } \\
\text { Bibliográfica }\end{array}$} & \multirow[t]{2}{*}{ Coleta } & \multirow[t]{2}{*}{ Triagem } & \multirow[t]{2}{*}{ Destinação } & \multirow[t]{2}{*}{$\begin{array}{l}\text { Transpo } \\
\text { rte }\end{array}$} & \multicolumn{3}{|c|}{ Processamento } & \multirow{2}{*}{$\begin{array}{l}\text { Des } \\
\text { cart } \\
\text { e } \\
\text { Ater } \\
\text { ro } \\
\text { Sani } \\
\text { tário }\end{array}$} & \multicolumn{2}{|c|}{$\begin{array}{l}\text { Planta } \\
\text { Intermediária }\end{array}$} \\
\hline & & & & & & $\begin{array}{l}\mathrm{R} \\
\mathrm{E} \\
\mathrm{C}\end{array}$ & $\begin{array}{l}\mathrm{CO} \\
\mathrm{MP}\end{array}$ & $\begin{array}{l}\mathrm{CC} \\
\mathrm{RE}\end{array}$ & & Tipo & $\begin{array}{l}\text { Ativid } \\
\text { ade }\end{array}$ \\
\hline China & Li et al., 2011_b & - & $\begin{array}{l}\text { Estação de } \\
\text { transferência }\end{array}$ & $\begin{array}{l}\text { Estação de } \\
\text { transferência }\end{array}$ & TRANSF & $\mathrm{x}$ & - & $\mathrm{x}$ & $\begin{array}{l}\text { Aterr } \\
\text { o } \\
\text { sanit } \\
\text { ário }\end{array}$ & $\begin{array}{l}\text { Esta } \\
\text { ção } \\
\text { de } \\
\text { TRA } \\
\text { NSF }\end{array}$ & $\begin{array}{l}\text { Compa } \\
\text { ctação, } \\
\text { triage } \\
\text { m e } \\
\text { destina } \\
\text { ção }\end{array}$ \\
\hline Portugal & $\begin{array}{l}\text { Pires et al., } \\
2011\end{array}$ & Coleta seletiva mista & $\begin{array}{l}\text { Geração, } \\
\text { centro de } \\
\text { triagem e } \\
\text { estação de } \\
\text { transferência }\end{array}$ & $\begin{array}{l}\text { Geração, centro de } \\
\text { triagem e estação de } \\
\text { transferência }\end{array}$ & $\begin{array}{l}\text { Coleta e } \\
\text { TRANSF }\end{array}$ & $x$ & $x$ & $\mathrm{x}$ & $\begin{array}{l}\text { Aterr } \\
\text { o } \\
\text { sanit } \\
\text { ário }\end{array}$ & $\begin{array}{l}\text { Esta } \\
\text { ção } \\
\text { de } \\
\text { TRA } \\
\text { NSF }\end{array}$ & $\begin{array}{l}\text { Consol } \\
\text { idação, } \\
\text { triage } \\
\text { me } \\
\text { destina } \\
\text { ção }\end{array}$ \\
\hline & & & & & & & & & & $\begin{array}{l}\text { Cent } \\
\text { ro } \\
\text { de } \\
\text { triag } \\
\text { em }\end{array}$ & $\begin{array}{l}\text { Proces } \\
\text { so de } \\
\text { TMB }^{*}\end{array}$ \\
\hline $\begin{array}{l}\text { Estados } \\
\text { Unidos }\end{array}$ & $\begin{array}{l}\text { Chang et al., } \\
2012\end{array}$ & Coleta seletiva & $\begin{array}{l}\text { Geração e } \\
\text { Centro de } \\
\text { triagem }\end{array}$ & $\begin{array}{l}\text { Geração e Centro de } \\
\text { triagem }\end{array}$ & $\begin{array}{l}\text { Coleta e } \\
\text { TRANSF }\end{array}$ & $\mathrm{x}$ & - & - & $\begin{array}{l}\text { Aterr } \\
\text { o } \\
\text { sanit } \\
\text { ário } \\
\text { com } \\
\text { RE }\end{array}$ & $\begin{array}{l}\text { Cent } \\
\text { ro } \\
\text { de } \\
\text { triag } \\
\text { em }\end{array}$ & $\begin{array}{l}\text { Triage } \\
\text { m e } \\
\text { destina } \\
\text { ção de } \\
\text { reciclá } \\
\text { veis ** }\end{array}$ \\
\hline China & Lu et al., 2012 & Coleta indiferenciada & - & - & TRANSF & - & - & $x$ & $\begin{array}{l}\text { Aterr } \\
\text { o } \\
\text { sanit } \\
\text { ário }\end{array}$ & - & - \\
\hline Canadá & $\begin{array}{l}\text { Huang et al., } \\
2012\end{array}$ & Coleta seletiva & Geração & Geração & $\begin{array}{l}\text { Coleta e } \\
\text { TRANSF }\end{array}$ & - & $x$ & $\mathrm{x}$ & $\begin{array}{l}\text { Aterr } \\
\text { o } \\
\text { sanit } \\
\text { ário }\end{array}$ & - & - \\
\hline Itália & $\begin{array}{l}\text { Ionescu et al., } \\
2013\end{array}$ & Coleta seletiva & $\begin{array}{l}\text { Geração e } \\
\text { centro de } \\
\text { triagem }\end{array}$ & $\begin{array}{l}\text { Geração e centro de } \\
\text { triagem }\end{array}$ & - & $\mathrm{x}$ & $\mathrm{x}$ & $\mathrm{x}$ & $\begin{array}{l}\text { Aterr } \\
\text { o } \\
\text { sanit } \\
\text { ário }\end{array}$ & $\begin{array}{l}\text { Cent } \\
\text { ro } \\
\text { de } \\
\text { triag } \\
\text { em }\end{array}$ & $\begin{array}{l}\text { Triage } \\
\text { m e } \\
\text { destina } \\
\text { ção }\end{array}$ \\
\hline $\begin{array}{l}\text { Estados } \\
\text { Unidos }\end{array}$ & $\begin{array}{l}\text { Levis et al., } \\
2013\end{array}$ & $\begin{array}{l}\text { Coleta seletiva com } \\
\text { ponto de entrega } \\
\text { voluntária }\end{array}$ & Geração & Geração & $\begin{array}{l}\text { Coleta e } \\
\text { TRANSF }\end{array}$ & $\mathrm{x}$ & $x$ & $\mathrm{x}$ & $\begin{array}{l}\text { Aterr } \\
\text { o } \\
\text { sanit } \\
\text { ário }\end{array}$ & - & - \\
\hline Grécia & $\begin{array}{l}\text { Komilis e } \\
\text { Minoglou, } 2013\end{array}$ & $\begin{array}{l}\text { Coleta seletiva com } \\
\text { ponto de entrega }\end{array}$ & $\begin{array}{l}\text { Geração e } \\
\text { centro }\end{array}$ & $\begin{array}{l}\text { Estação de } \\
\text { transferência e centro }\end{array}$ & TRANSF & $x$ & $x$ & $\mathrm{x}$ & $\begin{array}{l}\text { Aterr } \\
\text { o }\end{array}$ & $\begin{array}{l}\text { Esta } \\
\text { ção }\end{array}$ & $\begin{array}{l}\text { Consol } \\
\text { idação }\end{array}$ \\
\hline
\end{tabular}




\begin{tabular}{|c|c|c|c|c|c|c|c|c|c|c|c|}
\hline & & voluntária & $\begin{array}{l}\text { integrado de } \\
\text { gestão do } \\
\text { RSU }\end{array}$ & $\begin{array}{l}\text { integrado de gestão } \\
\text { do RSU }\end{array}$ & & & & & $\begin{array}{l}\text { sanit } \\
\text { ário }\end{array}$ & $\begin{array}{l}\text { de } \\
\text { TRA } \\
\text { NSF }\end{array}$ & \\
\hline & & & & & & & & & & $\begin{array}{l}\text { Cent } \\
\text { ro } \\
\text { integ } \\
\text { rado } \\
\text { de } \\
\text { gest } \\
\text { âo } \\
\text { do } \\
\text { RSU }\end{array}$ & $\begin{array}{l}\text { Proces } \\
\text { so de } \\
\text { TMB } \\
\star \star \star \star\end{array}$ \\
\hline China & $\begin{array}{l}\text { Zhang e Huang, } \\
2013\end{array}$ & Coleta indiferenciada & - & - & TRANSF & - & - & $x$ & $\begin{array}{l}\text { Aterr } \\
\text { o } \\
\text { sanit } \\
\text { ário }\end{array}$ & - & - \\
\hline
\end{tabular}

Tabela 2 - Continuação: Classificação das Atividades do Sistema Logístico Reverso do RSU.

\begin{tabular}{|c|c|c|c|c|c|c|c|c|c|c|c|}
\hline \multirow[t]{2}{*}{ País } & \multirow[t]{2}{*}{$\begin{array}{l}\text { Referência } \\
\text { Bibliográfica }\end{array}$} & \multirow[t]{2}{*}{ Coleta } & \multirow[t]{2}{*}{ Triagem } & \multirow[t]{2}{*}{ Destinação } & \multirow[t]{2}{*}{ Transporte } & \multicolumn{3}{|c|}{ Processamento } & \multirow{2}{*}{$\begin{array}{l}\begin{array}{l}\text { Des } \\
\text { cart } \\
\text { e }\end{array} \\
\text { Ater } \\
\text { ro } \\
\text { Sani } \\
\text { tário }\end{array}$} & \multicolumn{2}{|c|}{$\begin{array}{l}\text { Planta } \\
\text { Intermediária }\end{array}$} \\
\hline & & & & & & REC & $\begin{array}{l}\text { CO } \\
\text { MP }\end{array}$ & $\begin{array}{l}\text { CC } \\
\text { RE. }\end{array}$ & & Tipo & $\begin{array}{l}\text { Ativid } \\
\text { ade }\end{array}$ \\
\hline \multirow[t]{2}{*}{$\begin{array}{l}\text { Gré } \\
\text { cia }\end{array}$} & \multirow[t]{2}{*}{$\begin{array}{l}\text { Mavrotas et } \\
\text { al., } 2013\end{array}$} & \multirow{2}{*}{$\begin{array}{l}\text { Coleta } \\
\text { seletiva } \\
\text { com } \\
\text { ponto de } \\
\text { entrega } \\
\text { voluntária }\end{array}$} & \multirow{2}{*}{$\begin{array}{l}\text { Geração, } \\
\text { estação de } \\
\text { transferência e } \\
\text { centro de } \\
\text { triagem }\end{array}$} & \multirow[t]{2}{*}{$\begin{array}{l}\text { Geração, estação de } \\
\text { transferência e centro de } \\
\text { triagem }\end{array}$} & \multirow[t]{2}{*}{ Coleta e TRANSF } & \multirow[t]{2}{*}{$x$} & \multirow[t]{2}{*}{$x$} & \multirow[t]{2}{*}{$x$} & \multirow[t]{2}{*}{$\begin{array}{l}\text { Aterr } \\
0 \\
\text { sanit } \\
\text { ário }\end{array}$} & $\begin{array}{l}\text { Estaç } \\
\text { ão de } \\
\text { TRAN } \\
\text { SF }\end{array}$ & $\begin{array}{l}\text { Triage } \\
\text { m e } \\
\text { destin } \\
\text { ação }\end{array}$ \\
\hline & & & & & & & & & & $\begin{array}{l}\text { Centro } \\
\text { de } \\
\text { triage } \\
\mathrm{me} \\
\mathrm{PP} \text { de } \\
\mathrm{RDF} \\
\end{array}$ & $\begin{array}{l}\text { Proces } \\
\text { so de } \\
\text { TMB }\end{array}$ \\
\hline $\begin{array}{l}\text { Chin } \\
\text { a }\end{array}$ & $\begin{array}{l}\text { Wang et al., } \\
2013\end{array}$ & $\begin{array}{l}\text { Coleta } \\
\text { seletiva } \\
\text { com } \\
\text { ponto de } \\
\text { entrega } \\
\text { voluntária } \\
\end{array}$ & $\begin{array}{l}\text { Geração e } \\
\text { centro de } \\
\text { triagem }\end{array}$ & $\begin{array}{l}\text { Geração e centro de } \\
\text { triagem }\end{array}$ & Coleta e TRANSF & $x$ & - & $\mathrm{x}$ & $\begin{array}{l}\text { Aterr } \\
\text { o } \\
\text { sanit } \\
\text { ário }\end{array}$ & $\begin{array}{l}\text { Centro } \\
\text { de } \\
\text { triage } \\
\mathrm{m}\end{array}$ & $\begin{array}{l}\text { Triage } \\
\mathrm{m} \text { de } \\
\text { resídu } \\
\text { o tipo } \\
\text { metal * }\end{array}$ \\
\hline $\begin{array}{l}\text { Chin } \\
\text { a }\end{array}$ & $\begin{array}{l}\text { Chi et al., } \\
2014\end{array}$ & - & - & - & - & - & - & $\mathrm{x}$ & $\begin{array}{l}\text { Aterr } \\
\text { o } \\
\text { sanit } \\
\text { ário } \\
\text { com } \\
\text { RE } \\
\end{array}$ & - & - \\
\hline Itália & $\begin{array}{l}\text { Moedinger et } \\
\text { al., } 2014\end{array}$ & $\begin{array}{l}\text { Coleta } \\
\text { seletiva }\end{array}$ & $\begin{array}{l}\text { Geração e } \\
\text { planta } \\
\text { intermediária }\end{array}$ & $\begin{array}{l}\text { Geração e planta } \\
\text { intermediária }\end{array}$ & - & $x$ & $x$ & $\mathrm{x}$ & $\begin{array}{l}\text { Aterr } \\
\text { o } \\
\text { sanit } \\
\text { ário }\end{array}$ & $\begin{array}{l}\text { Planta } \\
\text { interm } \\
\text { ediária }\end{array}$ & $\begin{array}{l}\text { Triage } \\
\text { m, } \\
\text { destin } \\
\text { ação, } \\
\text { secag } \\
\text { em e } \\
\text { diminui } \\
\text { ção de } \\
\text { granul } \\
\text { ometri } \\
\text { a }\end{array}$ \\
\hline $\begin{array}{l}\text { Esp } \\
\text { anh } \\
\text { a }\end{array}$ & $\begin{array}{l}\text { Fernández- } \\
\text { Nava et al., } \\
2014\end{array}$ & $\begin{array}{l}\text { Coleta } \\
\text { seletiva }\end{array}$ & $\begin{array}{l}\text { Geração e } \\
\text { centro de } \\
\text { triagem }\end{array}$ & $\begin{array}{l}\text { Geração e centro de } \\
\text { triagem }\end{array}$ & Coleta e TRANSF & $\mathrm{x}$ & $x$ & $\mathrm{x}$ & $\begin{array}{l}\text { Aterr } \\
\text { o } \\
\text { sanit } \\
\text { ário } \\
\text { com } \\
\text { RE }\end{array}$ & $\begin{array}{l}\text { Centro } \\
\text { de } \\
\text { triage } \\
\mathrm{m}\end{array}$ & $\begin{array}{l}\text { Triage } \\
m \text { e } \\
\text { destin } \\
\text { ação }\end{array}$ \\
\hline \multirow[t]{2}{*}{$\begin{array}{l}\text { Port } \\
\text { ugal }\end{array}$} & \multirow[t]{2}{*}{$\begin{array}{l}\text { Roca et al., } \\
2014\end{array}$} & \multirow[t]{2}{*}{$\begin{array}{l}\text { Coleta } \\
\text { seletiva } \\
\text { mista }\end{array}$} & \multirow[t]{2}{*}{$\begin{array}{l}\text { Geração, centro } \\
\text { de triagem e } \\
\text { estação de } \\
\text { transferência }\end{array}$} & \multirow[t]{2}{*}{$\begin{array}{l}\text { Centro de triagem e } \\
\text { estação de transferência }\end{array}$} & \multirow[t]{2}{*}{ Coleta e TRANSF } & \multirow[t]{2}{*}{$x$} & \multirow[t]{2}{*}{$x$} & \multirow[t]{2}{*}{$x$} & \multirow[t]{2}{*}{$\begin{array}{l}\text { Aterr } \\
\text { o } \\
\text { sanit } \\
\text { ário }\end{array}$} & $\begin{array}{l}\text { Centro } \\
\text { de } \\
\text { triage } \\
\mathrm{m}\end{array}$ & $\begin{array}{l}\text { Pré- } \\
\text { tratam } \\
\text { ento } \\
\text { de } \\
\text { reciclá } \\
\text { vel, } \\
\text { triage } \\
\text { m e } \\
\text { destin } \\
\text { ação }\end{array}$ \\
\hline & & & & & & & & & & $\begin{array}{l}\text { Estaç } \\
\text { ão de } \\
\text { TRAN } \\
\text { SF } \\
\end{array}$ & $\begin{array}{l}\text { Triage } \\
\mathrm{m} \text { e } \\
\text { destin } \\
\text { ação } \\
\end{array}$ \\
\hline
\end{tabular}

${ }^{*}$ Centro de triagem na mesma localidade da planta de combustão com recuperação energética.

Tabela 2 - Continuação: Classificação das Atividades do Sistema Logístico Reverso do RSU.

\begin{tabular}{|c|c|c|c|c|c|c|c|c|c|c|c|}
\hline \multirow[t]{2}{*}{ País } & \multirow[t]{2}{*}{$\begin{array}{l}\text { Referência } \\
\text { Bibliográfica }\end{array}$} & \multirow[t]{2}{*}{ Coleta } & \multirow[t]{2}{*}{ Triagem } & \multirow[t]{2}{*}{ Destinação } & \multirow[t]{2}{*}{$\begin{array}{l}\text { Transport } \\
\text { e }\end{array}$} & \multicolumn{3}{|c|}{ Processamento } & \multirow{2}{*}{$\begin{array}{l}\text { Desc } \\
\text { arte } \\
\text { Aterr } \\
\text { o } \\
\text { Sanit } \\
\text { ário }\end{array}$} & \multicolumn{2}{|c|}{$\begin{array}{l}\text { Planta } \\
\text { Intermediária }\end{array}$} \\
\hline & & & & & & $\begin{array}{l}\text { RE } \\
\mathrm{C}\end{array}$ & $\begin{array}{l}\text { CO } \\
\text { MP }\end{array}$ & $\begin{array}{l}\text { CCR } \\
\text { E. }\end{array}$ & & Tipo & $\begin{array}{l}\text { Ativida } \\
\text { de }\end{array}$ \\
\hline China & $\begin{array}{l}\text { Zhang et al., } \\
2014\end{array}$ & $\begin{array}{l}\text { Coleta } \\
\text { indiferenciada } \\
\text { com ponto de } \\
\text { entrega }\end{array}$ & $\begin{array}{l}\text { Estação de } \\
\text { transferência }\end{array}$ & $\begin{array}{l}\text { Estação de } \\
\text { transferência }\end{array}$ & $\begin{array}{l}\text { Coleta e } \\
\text { TRANSF }\end{array}$ & - & - & $x$ & $\begin{array}{l}\text { Aterro } \\
\text { sanitá } \\
\text { rio }\end{array}$ & $\begin{array}{l}\text { Estaç } \\
\text { ão de } \\
\text { TRA } \\
\text { NSF }\end{array}$ & $\begin{array}{l}\text { Triagem } \\
\mathrm{e} \\
\text { destinaç } \\
\text { ão }\end{array}$ \\
\hline Índia & $\begin{array}{l}\text { Ravindra et al., } \\
2015\end{array}$ & $\begin{array}{l}\text { Coleta } \\
\text { indiferenciada } \\
\text { porta-a-porta }\end{array}$ & $\begin{array}{l}\text { Geração e } \\
\text { Estação de } \\
\text { transferência } \\
\text { * }\end{array}$ & $\begin{array}{l}\text { Geração e } \\
\text { Estação de } \\
\text { transferência } \\
*\end{array}$ & $\begin{array}{l}\text { Coleta e } \\
\text { TRANSF }\end{array}$ & $x$ & $x$ & - & Lixão & $\begin{array}{l}\text { Estaç } \\
\text { ão de } \\
\text { TRA } \\
\text { NSF }\end{array}$ & $\begin{array}{l}\text { Consolid } \\
\text { ação }\end{array}$ \\
\hline & & & & & & & & & & $\begin{array}{l}\text { PP } \\
\text { do } \\
\text { RDF }\end{array}$ & $\begin{array}{l}\text { Triagem } \\
\text { destinaç }\end{array}$ \\
\hline
\end{tabular}




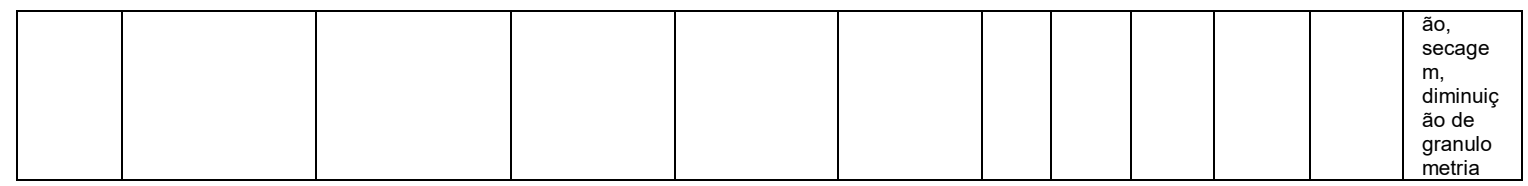

\section{RESULTADOS}

A partir da revisão bibliográfica, detalha-se cada atividade de coleta, triagem, destinação, transporte, processamento e descarte apresentadas na Tabela 2. A planta intermediária será analisada de acordo com a sua tipologia e atividades exercidas. E os detalhamentos das atividades de triagem e destinação serão apresentados de forma integrada, pois são atividades complementares e subsequentes.

\section{Coleta}

Existem dois sistemas de coleta de resíduos sólidos domiciliares: indiferenciada e seletiva. A coleta indiferenciada é o recolhimento de resíduos recicláveis e não recicláveis sem distinção. Já a coleta seletiva é o recolhimento de resíduos recicláveis de forma distinta dos demais resíduos (SMA/CEA, 2011). Na literatura também se encontra a coleta seletiva separada por resíduos secos e úmidos, onde o resíduo úmido contempla o resíduo orgânico com possibilidade de compostagem, e o resíduo seco como os demais resíduos com possibilidade de reciclagem ou descarte (EPA, 1995; SRHU/MMA, 2011).

Na coleta seletiva, o RSU é previamente separado pela fonte geradora. Esta separação pode ocorrer de três formas: porta-a-porta, em pontos de entrega voluntária (PEV) ou mista (SMA/CEA, 2011). Na coleta indiferenciada, na maioria dos casos, ocorre porta-a-porta. Porém há casos de coleta indiferenciada onde o gerador precisa levar o resíduo até um ponto de entrega, estes casos podem ser vistos em Hui et al. (2006) e Zhang et al. (2014). Além disso, existem casos específicos na Índia onde a coleta porta-a-porta é realizada com carrinho de mão por recursos contratados pelos municípios e encaminhados a um ponto de entrega para consolidação. Dutta et al. (2009) apresentam este processo por meio da coleta indiferenciada e Taylan et al. (2008) na coleta seletiva.

$\mathrm{Na}$ China e na Índia a estrutura de coleta do resíduo reciclável é realizada por um processo completamente informal e sem apoio do poder público. Este processo pode ser observado em Hui et al. (2006), Taylan et al. (2008), Dutta et al. (2009), Zhang et al. (2010), Li et al. (2011a) e Ravindra et al. (2015). Na China, muitas vezes os residentes vendem os resíduos de forma direta às unidades recicladoras ou por intermédio de grupos de pessoas que fazem a coleta do resíduo nas ruas para venda posterior. Cerca de $12 \%$ de todo RSU gerado na China é gerido desta maneira (ZHANG et al. 2010). 


\section{Triagem e Destinação}

As atividades de triagem e destinação podem ocorrer juntas em uma mesma facilidade ou não, porém sempre são atividades de ocorrência próxima. Quando ocorrem de forma integrada, geralmente ocorrem na geração e lou em alguma planta intermediária entre as atividades de coleta e processamento. Verificam-se casos em que estas atividades ocorrem de forma integrada mais de uma vez dentro do mesmo sistema. Semiao et al. (2006), Hong-tao et al. (2007), Yeomans (2007), Erkut et al. (2008), Warith et al. (2008), Robba et al. (2008), Messineo e Panno (2008), Zhen-shan et al. (2009), Bovea et al. (2010), Pires et al. (2011), Chang et al. (2012), Wang et al. (2013), lonescu et al. (2013), Mavrotas et al. (2013) e Fernández-Nava et al. (2014) apresentam um sistema logístico reverso do RSU em que as atividades de triagem e destinação ocorrem tanto na geração quanto no centro de triagem e/ou na estação de transferência.

Quando as atividades de triagem e destinação ocorrem de forma separada, normalmente ocorrem em processos subsequentes, como apresentados por Taylan et al. (2008), Galante et al. (2010), Huang et al. (2011), Komilis e Minoglou (2013) e Rocca et al. (2014). Como exemplo, em Huang et al. (2011) a triagem ocorre na geração através da coleta seletiva, porém todos os tipos de resíduos são encaminhados para a estação de transferência sem distinção. A destinação para a valorização ocorre na estação de transferência. Além disso, em alguns países em desenvolvimento estas atividades podem ser realizadas pelo setor informal, exclusivamente para a triagem e destinação de resíduos recicláveis. Hui et al. (2006), Taylan et al. (2008), Dutta el al. (2009), Zhang et al. (2010), Li et al. (2011_a) e Ravindra et al. (2015) apresentam este tipo de sistema, em que estas atividades ocorrem na coleta porta-a-porta e/ou no ponto de entrega onde o resíduo é consolidado. Talyan et al. (2008) ainda apresenta as atividades de triagem e destinação de resíduos recicláveis nos lixões.

\section{Transporte}

A atividade de transporte do resíduo pode ser classificada em dois tipos, com características distintas: transporte para coleta e transporte para transferência. $O$ transporte na atividade de coleta é a primeira etapa de movimentação do resíduo, que se origina nos geradores e se destina à atividade subsequente, que pode ser em uma planta intermediária nas unidades de processamento ou para descarte. O transporte para transferência do RSU ocorre após a primeira movimentação do resíduo na coleta, podendo ser de diversas origens para diversos destinos, sendo na planta intermediária, planta de processamento e descarte.

O modelo de transporte da coleta é complexo e custoso, tendo a necessidade de analisar a demanda de cada área e montar um roteiro de coleta para otimização do uso dos veículos. As viaturas de coleta do resíduo domiciliar podem ser de dois tipos: veículos equipados com equipamentos compactadores ou sem estes equipamentos (IBAM, 2001). Os veículos com 
equipamentos compactadores são os mais comuns na atividade de coleta e dispõem de um compactador hidráulico que permite aumentar a quantidade de resíduos coletados (EPA, 1995). A escolha do tipo do veículo depende de como está estruturado o sistema de coleta, ou seja, depende da quantidade de RSU gerado na região e das características físicas da rota de coleta (IBAM, 2001; EPA, 1995).

Já quando há um entreposto, sendo este para o transbordo do resíduo para consolidação ou uma unidade de processamento de resíduo, o modelo de transporte apresenta características diferentes da coleta para o sistema de transporte a partir deste ponto. A transferência do RSU destes pontos para a próxima destinação é realizada com veículos de maior porte, cerca de 3 vezes maior do que o veículo de coleta, possuindo carroceria de $45 \mathrm{~m}^{3}$ ou com fundo móvel (IBAM, 2001).

Segundo EPA (1995), mesmo na transferência pode ser utilizado semi-reboque com equipamentos compactadores. Este processo pode ser visto em Li'ao et al. (2009), em que a planta intermediária apresentada no sistema é responsável pela atividade de consolidação. Assim, o veículo com equipamento compactador é utilizado para diminuição do volume de resíduo para o descarte no aterro sanitário.

O transporte de transferência do resíduo do entreposto para o local de descarte não precisa ser necessariamente via modo rodoviário. Cidades como Nova York e Seattle utilizam barcaças para transferência de RSU para os aterros sanitários (EPA, 1974). Além disso, nos EUA, cerca de $5 \%$ do volume de transferência de RSU são realizados por ferrovias, ocorrendo nas cidades de Seattle, Washington, Portland, Oregon e a região sudeste de Massachusetts.

\section{Processamento}

A atividade de processamento consiste na valorização do RSU por meio de três possíveis métodos: a reciclagem, compostagem e a combustão com recuperação energética. A escolha de qual método a ser utilizado no sistema depende diretamente da estruturação das atividades de triagem e destinação e do tipo de resíduo disponível. A reciclagem consiste na valorização do resíduo por meio de reparo ou tratamento, para propósitos similares ao do produto de onde este material foi originado. De acordo com EPA (1995), podem ser reciclados materiais do tipo papel e papelão, metais em geral, vidro e plástico. A tecnologia e o processo a serem utilizados são diferentes para cada tipo de material e exigências do mercado de destino.

Já a compostagem é um processo controlado de decomposição biológica da matéria orgânica presente no resíduo, no qual se utiliza micro-organismos existentes nos resíduos em condições adequadas de aeração, umidade e temperatura. Esse processo gera um produto biologicamente estável chamado composto orgânico, que podem servir de fertilizantes para a produção agrícola. Para a inserção do resíduo neste processo, há a necessidade de triagem dos resíduos orgânicos e de diminuição de granulometria (SMA/CEA, 2011; EPA, 1995; EPA, 2011). 
O método de combustão para recuperação energética, também conhecida como processo 'waste-to-energy' (WTE), iniciou-se nos EUA por volta de 1980. Antes disso, a combustão tinha o objetivo simplesmente de redução de volume do resíduo para o envio posterior ao aterro sanitário.

O processo WTE pode ocorrer de algumas formas: através da combustão direta que pode ser realizada pelo método de incineração, pirólise ou gaseificação, ou através da utilização do resíduo como combustível sólido, também podendo ser chamado de refuse derived fuel (RDF), onde este combustível pode ser encaminhado para outras indústrias e utilizado como substituto de um combustível fóssil (CHENG \& HU, 2010; EC, 2010; ABRELPE \& PLASTIVIDA, 2012; OLIVEIRA \& ROSA, 2003; MCKAY et al., 2004). Em todos os processos de combustão com valorização energética há a necessidade de triagem do resíduo. Além disso, nos métodos de gaseificação e pirólise realiza-se um pré-tratamento com diminuição do volume do resíduo e em alguns casos, a secagem dos mesmos. Já no processo de produção do combustível sólido o processo de triagem e diminuição de volume são mais específicos, em que na triagem é necessária a retirada de metais ferrosos e a granulometria nominal máxima do resíduo deve ser entre 10 a 15 centímetros para a transformação em RDF (EPA, 1995; CHENG \& HU, 2010; EC, 2010; ABRELPE \& PLASTIVIDA, 2012).

Os métodos de incineração, pirólise ou gaseificação, além da recuperação energética, geram rejeitos como resultados do processo, havendo a necessidade de transferência para descarte em aterros sanitários (CHENG \& HU, 2010; EPA, 1974; EC, 2010). Apesar dos métodos de tratamento serem processos complementares e não excludentes entre si, percebe-se que nem todos os sistemas logísticos reversos do RSU apresentam estas três formas de processamento. Dentre os 43 artigos analisados, apenas em 18 casos apresentam a estrutura de valorização integrada com a utilização dos três métodos.

\section{Descarte}

O descarte do RSU pode ocorrer de duas formas: descarte direto para aterros sanitários ou o envio ao aterro sanitário após o processamento do resíduo. O envio do resíduo diretamente ao aterro sanitário é a forma mais comum de disposição, com o menor custo operacional e necessidade de capital, porém é a pior maneira sob a ótica ambiental e de utilização do solo. Existem duas formas de processamento com o objetivo de diminuição do volume do resíduo para disposição final: por meio de trituração e enfardamento ou pelo processo de combustão sem recuperação energética, que tem a possibilidade de diminuição do volume do resíduo em até $90 \%$. Estes processos são benéficos sob a ótica da utilização do solo, porém ainda há a necessidade de envio do rejeito ao aterro sanitário (EPA, 1974).

Entende-se que a utilização da combustão sem recuperação energética é um método ultrapassado, levando em consideração a revisão bibliográfica realizada. Em nenhum dos sistemas logísticos reversos analisados, há a indicação deste método. Todos os métodos de 
combustão analisados foram através da recuperação energética. Todavia, EPA (1995) evidencia a possibilidade de coleta de gases nos aterros sanitários como uma potencial fonte de energia. Hong-tao et al. (2007), Bovea et al. (2010), Su et al. (2010) Chang et al. (2012), Fernández-Nava et al. (2014) e Chi et al. (2014) apresentam sistemas logístico reversos do RSU com o descarte de resíduos e rejeitos em aterros sanitários com recuperação energética.

No Brasil, existe a possibilidade de envio do resíduo para descarte em aterros controlados e lixões. Os aterros controlados são locais que não possuem coleta e tratamento do chorume, assim como drenagem e queima de biogás. Nos lixões o lançamento do resíduo é feito a céu aberto com uma simples descarga ao solo, sem nenhum tipo de proteção ao meio ambiente (ABRELPE, 2013; IBAM, 2001). Dutta et al. (2009), Ravindra et al. (2015) e Talyan et al. (2008) também apresentam estudos de casos na Índia, em que os sistemas apresentam o descarte em lixões.

Um dos grandes problemas ambientais causados pelo descarte dos resíduos em aterros é a geração do metano, que tem potencial de aquecimento global 25 vezes mais intenso se comparado ao dióxido de carbono. Ao mesmo tempo, esta é uma prática onde há a necessidade de grande área de uso do solo e pode resultar em problemas ambientais de forma secundária, como contaminação de solo e de lençóis freáticos, poluição do ar, além de servir como terreno fértil para pragas e doenças (CHENG \& HU, 2010; EC, 2010). Além dos impactos ambientais do descarte, o histórico da evolução da gestão de resíduos nos países desenvolvidos mostra uma tendência dos órgãos reguladores em dificultar o envio do RSU aos aterros sanitários, fazendo com que diminua a quantidade de aterros sem condições ambientais adequadas e aumente o valor da taxa de despejo do resíduo nos aterros sanitários.

\section{Planta Intermediária}

Em muitos casos, o sistema logístico reverso do RSU estrutura-se com o apoio de uma planta intermediária. $\mathrm{Na}$ Tabela 2, observam-se nomenclaturas e atividades diversas que constituem esta facilidade. A nomenclatura para definição desta planta não é concisa na literatura acadêmica, podendo ser apresentada como estação de transferência, centro de triagem, centro integrado de gestão do RSU e planta de produção do RDF. Além disso, as atividades apresentadas não têm uma relação direta com nenhum tipo de nomenclatura estabelecida. Dessa forma, utiliza-se neste trabalho a nomenclatura 'estação de transferência' para qualquer tipo de planta intermediária, com o intuito de simplificação.

As atividades apresentadas na estação de transferência são: consolidação, compactação, triagem, destinação, pré-tratamento para a atividade de processamento ou descarte, secagem, diminuição de granulometria e produção de RDF. Estas atividades apresentam-se de forma isolada ou integrada. Feo e Malvano (2009), Pires et al. (2011), Komilis e Minoglou (2013) e 
Mavrotas et al. (2013), apresentam ainda o processo de tratamento mecânico-biológico (TMB) como atividade na planta intermediária.

O processo TMB consiste na triagem de resíduos através de processos físicos, como a utilização de eletro ímã e corrente de ar. Após este processo o resíduo passa por um processo de picagem e peneiramento. A fração mais fina do composto pode ser tratada em usinas de compostagem para a geração de um produto com potencial fertilizante. A fração mais grossa do composto se torna um material com alto poder calorífico para substituição energética, podendo ser utilizada no método de combustão com recuperação energética (ROBBA et al., 2004; STEHLÍK et al., 2012; FEAM, 2010).

Além disso, Pires et al. (2011), Chang et al. (2012), Komilis e Minoglou (2013) e Wang et al. (2013), apresentam o sistema em que a estação de transferência está integrada junto a alguma planta de processamento ou aterro sanitário. Apesar das atividades diversas que são executadas por esta facilidade, entende-se que todas as atividades são para consolidação ou para tratamento do resíduo para envio à atividade subsequente, que pode ser uma planta de processamento ou de descarte. A necessidade de consolidação do RSU decorre do aumento da dificuldade de instalações de aterros sanitários e plantas de processamento perto dos grandes geradores, por motivos sociais e econômicos. Com o aumento da distância entre o ponto de coleta e de processamento ou descarte, são implantadas estações de transferência com o intuito de diminuir a improdutividade dos veículos de coleta (IBAM, 2001; EPA, 1995; SMA/CEA, 2011).

Observa-se que quanto maior é a quantidade de atividades realizadas na estação de transferência, maior é a possibilidade de destinação do RSU para diversos métodos de valorização. Dessa forma, a estação de transferência, além de proporcionar melhoria no sistema através da otimização da atividade de coleta, pode apoiar também na integração do sistema logístico reverso do RSU facilitando a utilização de diversos métodos de valorização.

\section{DISCUSSÃO}

A partir do detalhamento de cada atividade do sistema logístico reverso do RSU, propõe-se um modelo conceitual, apresentado na Figura 2, fundamentado principalmente nos modelos de Erkut et al. (2008), Robba et al. (2008) e Roca et al. (2014). Estes modelos foram selecionados por apresentarem um sistema mais integrado em comparação aos demais, com a utilização dos três métodos de valorização (reciclagem, compostagem e combustão com recuperação energética).

$\mathrm{Na}$ atividade de coleta, define-se o processo de destinação do resíduo após a atividade de coleta como 'suprimentos'. No processo de coleta seletiva os resíduos podem ser triados na forma de recicláveis e não-recicláveis ou secos e úmidos, podendo ser destinados diretamente para a unidade de reciclagem (resíduos recicláveis) e para a unidade de compostagem (resíduos úmidos). Os demais resíduos são encaminhados para a estação de transferência ou para 
descarte. No processo de coleta indiferenciada, o RSU pode passar pela estação de transferência com o intuito de triagem e destinação ou encaminhados diretamente para o descarte no aterro sanitário. As atividades de triagem e destinação são representadas na Figura 2 nas facilidades onde estas podem ser executadas, em que podem ocorrer tanto na coleta quanto na estação de transferência.

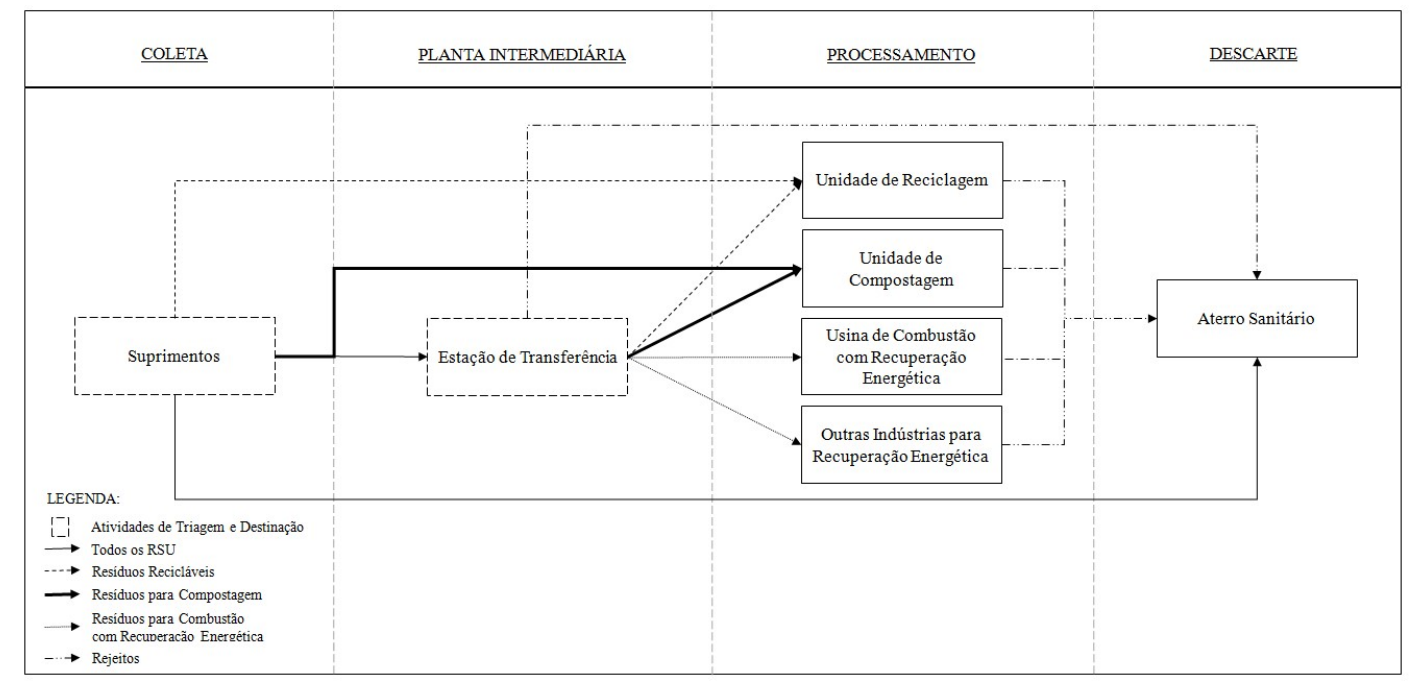

Figura 2: Modelo Conceitual do Sistema Logístico Reverso do RSU.

Fonte: Erkut et al. (2008), Robba et al. (2008) e Roca et al. (2014); adaptados.

A estação de transferência, neste caso, está estruturada para a realização das atividades de forma mais integrada possível, com as atividades de consolidação, triagem, diminuição de granulometria, produção de RDF e destinação para os respectivos métodos de valorização. A utilização de todos os métodos da hierarquia em uma mesma estrutura de sistema é possível e recomendável para a gestão integrada do resíduo. Na União Europeia pratica-se esta hierarquia há mais de 30 anos e os países que mais reduziram eficazmente a dependência do aterro sanitário tem alcançado esta meta combinando os processos de reciclagem, compostagem e recuperação energética (ABRELPE \& PLASTIVIDA, 2012).

Assim, o processamento está sendo representado na Figura 2 por todos os métodos de valorizações. No caso da combustão com recuperação energética, apresenta-se a usina específica para este processo e as indústrias com possibilidade de combustão do RDF. Nos métodos de processamento e valorização do RSU são gerados rejeitos que devem ser descartados de forma adequada em aterros sanitários, assim como, na estação de transferência, há a geração de rejeito, que são resíduos depois de esgotadas todas as possibilidades de tratamento, triagem e destinação para valorização.

A atividade de transporte é representada pelas setas na figura 2, em que são classificadas pelos tipos de resíduos e suas destinações. Neste caso, apresenta-se apenas o transporte para a transferência de resíduos. Já na atividade de descarte, foi considerado apenas o uso do aterro sanitário, pois o processo de combustão sem recuperação energética mostrou-se um método obsoleto para a atividade de descarte. 


\section{CONCLUSÕES}

Dessa forma, por meio da revisão bibliográfica narrativa, foi possível integrar os conceitos da logística reversa e da gestão de resíduos, além de identificar e detalhar as características do sistema logístico reverso do RSU, mostrando-se uma metodologia adequada para elaboração deste artigo, e possibilitando a elaboração do modelo conceitual do sistema logístico reverso do RSU. A limitação principal deste estudo é a consideração apenas de literatura originados no Brasil, Estados Unidos, Canadá, México, União Europeia, China e Índia. Dessa forma, recomenda-se para estudos futuros, a consideração de um número maior de estudos em locais diferenciados, podendo apresentar estruturas da logística reversa do RSU diferentes dos analisados neste trabalho.

\section{REFERÊNCIAS}

ABRELPE. Panorama dos resíduos sólidos no Brasil. São Paulo: Associação Brasileira de Empresas de Limpeza Pública e Resíduos Especiais, 2013.

ABRELPE e PLASTIVIDA. Caderno informativo resíduo sólido urbano - recuperação energética. São Paulo: Associação Brasileira de Empresas de Limpeza Pública e Resíduos Especiais e Instituto Sócio Ambiental dos Plásticos, 2012.

ABRELPE e ISWA. Resíduos sólidos: manual de boas práticas no planejamento. São Paulo: Associação Brasileira de Empresas de Limpeza Pública e Resíduos Especiais e International Solid Waste Association, 2013.

BOVEA, M. D.; IBÁÑEZ-FORÉS, V.; GALLARDO, A.; COLOMER-MENDOZA, F. J.. Environmental assessment of alternative municipal solid waste management strategies. A spanish case study. Waste Management, n.30, p. 2383-2395, 2010.

BRASIL. Lei $\mathbf{n}^{\circ} \mathbf{1 2 . 3 0 5}$ de 2 de agosto de 2010. Institui a política nacional de resíduos sólidos. Brasília, 2 de ago 2010.

CHANG N.; Qi, C., ISLAM, K.; HOSSAIN, F.. Comparisons between global warming potential and costbenefit criteria for optimal planning of a municipal solid waste management system. Journal of Cleaner Production, n.20, p.1-13, 2012.

CHEN, B.; LI, P.. FSILP: Fuzzy-stochastic-interval linear programming for supporting municipal solid waste management. Journal of Environmental Management, n.92, p.1198-1209, 2011.

CHENG, H.; HU, Y.. Municipal solid waste (MSW) as a renewable source of energy: current and future practices in China. Biosresource Technology. v.101, p.3816-3824, 2010.

CHI, J. D.Y.; FU, D. Z. C.; HUANG, Q.; NI, M.. Energy-environment-economy assessment of waste management systems from a life cycle perspective: model development and case study. Applied Energy. $\mathrm{n}$. 114, p.400-408, 2014.

DE BRITO, M. P.; DEKKER, R.. A Framework for Reverse Logistics. Rotterdam: Institute of Management Report Series Research In Management, 2003.

DUTTA, A.; CHATTOPADHYAY, S.; RAY, S.. Municipal solid waste management in Kolkata, India - a review. Waste Management, n. 29, p.1449-1458, 2009.

ERKUT, E.; KARAGIANNIDIS, A.; PERKOULIDIS, G.; TJANDRA, S. A.. A multicriteria facility location model for municipal solid waste management in north Greece. European Journal of Operational Research, $\mathrm{n}$. 187, p.1402-1421, 2008. 
EPA. Decision-makers guide in solid waste management. Washington: Environmental Protection Agency, 1974.

EPA. Decision-makers guide to solid waste management. Washington: Environmental Protection Agency, 1995.

EPA. Municipal solid waste in the United States: 2011 facts and figures., Washington: Environmental Protection Agency, 2011.

FEO, D.; MALVANO, C.. The use of LCA in selecting the best MSW management system. Waste Management, n. 29, p.1901-1915, 2009.

FERNÁNDEZ-NAVA, Y.; RÍO, J.; RODRÍGUEZ-IGLESIAS, J.; CASTRILLÓN, L.; MARAÑÓN, E.. Life cycle assessment of different municipal solid waste management options: a case study of Asturias (Spain). Journal of Cleaner Production. n.81, p.178-189, 2014.

FLEISCHMANN, M.; KRIKKE, H. R.; DEKKER, R.; FLAPPER, S. D. P.. A characterization of logistics networks for product recovery. Omega The International Journal of Management Science. n.28, p.653666, 2000.

GALANTE, G.; AIELLO, G.; ENEA, M.; PANASCIA, E.. A multi-objective approach to solid waste management. Waste Management, n.30, p.1720-1728, 2010.

HONG-TAO, W., BAO-GUO, T., JI-TAO, S., YAN, Z., JI-MING, H.. Approach of technical decision-making by element flow analysis and Monte-Carlo simulation of municipal solid waste stream. Journal of Environmental Science, n.19, p.633-640, 2007.

HUANG, G.H., XU, Y., QIN, X.S., CAO, M.F.. SRCCP: A stochastic robust chance-constrained programming model for municipal solid waste management under uncertainty. Resources, Conservation and Recycling, n.53, p.352-363, 2009

HUANG, G. H.; JING, S.; XI, B. D.; LI, Y. P.; QIN, X. S.; HUO, S. L., JIANG, Y.. A hybrid inexact optimization approach for solid waste management in the city of Foshan, China. Journal of Environmental Management. n.91, p.389-402, 2009.

HUANG, G. H.; LI, Y.P.; DAI, C.. A two-stage support-vector-regression optimization model for municipal solid waste management - a case study of Beijing, China. Journal of Environmental Management, n.92, p.3023-3037, 2011.

HUANG, G.H., ZHU, H.. SLFP: A stochastic linear fractional programming approach for sustainable waste management. Waste Management. n.31, p.2612-2619, 2011.

HUANG, G. H.; WANG, S.; YANG, B.T.. An interval-valued fuzzy-stochastic programming approach and its application to municipal solid waste management. Environmental Modelling \& Software, n.29, p.24-36, 2012.

HUI, Y., LI'AO W., FENWEI, S., GANG, H.. Urban solid waste management in Chogqing: challenges and opportunities. Waste Management. n. 26, p.1052-1062, 2006.

IBAM. Manual de gerenciamento integrado de resíduos sólidos. Brasil: Instituto Brasileiro de Administração Municipal, 2001.

IONESCU, G.; RADA, E. C.; RAGAZZI, M.; MARCULESCU, C.; BADEA, A.; APOSTOL, T.. Integrated municipal solid waste scenario model using advanced pretreatment and waste to energy processes. Energy Conservation and Management, n.76, p.1083-1092, 2013.

KOMILIS, D.; MINIGLOU, M.. Optimizing the treatment and disposal of municipal solid wastes using mathematical programming - a case study in a greek region. Resources, Conservation and Recycling, $\mathrm{n}$. 80, p.46-57, 2013.

LEVIS, J. W.; BARLAZ, M. A.; DECAROLIS, J. F.; RANJITHAN, S. R.. A generalized multistage optimization modeling framework for life cycle assessment-based integrated solid waste management. Environmental Modelling \& Software. n.50, p.51-65, 2013. 
LI, Y. P.; HUANG, G. H.; YANG, Z. F., NIE, S. L.. An integrated two-stage optimization model for the development of long-term waste-management strategies. Science of the Total Environment. n.392, p.175186, 2008.

LI, Y. P.; DAI, C.; HUANG, G. H.. A two-stage support-vector-regression optimization model for municipal solid waste management - a case study of Beijing, China. Journal of Environmental Management. n.92, p.3023-3037, 2011.

LI, Y. P.; CUI, L.; CHEN, L. R.; HUAN, G, H.; LI, W.; XIE, Y. L.. An interval-based regret-analysis method for identifying long-term municipal solid waste management policy under uncertainty. Journal of

Environmental Management, n.92, p.1484-1494, 2011.

LI'AO, W.; TING'QUAN, P.; CHUAN, H.; HUI, Y.. Management of municipal solid waste in the three gorges region. Waste Management. n.29, p.2203-2208, 2009.

LU, H. W.; HUANG, G. H.; XU, Y.; HE, L.. Inexact two-phase fuzzy programming and its application to municipal solid waste management. Engineering Applications of Artificial Intelligence. n.25, p.15291536, 2012.

MAVROTAS, G.; SKOULAXINOU, S.; GAKIS, N.; KATSOUROS, V.; GEORGOPOULOU, E.. A mulitobjective programming model for assessement the GHG emissions in MSW management. Waste Management. n.33, p.1934-1949, 2013.

MCKAY, G.; CHOY, K. K.H.; KO, D. C. K.; CHEUNG, W. H.; FUNG, J. S. C.; HUI, D. C. W.; PORTER, J. F.. Municipal solid waste utilization for integrated cement processing with waste minimization: a pilot scale proposal. Process Safety and Environmental Protection, v. 82, p.200-207, 2004.

MCKINNON, A.; CULLINANE, S.; BROWNE, M.; WHITEING, A.. Green logistics: Improving the environmental sustainability of logistics. Pittsburg: Kogan Page Limited, 2010.

MESSIONEO, A.; PANNO, D.. Municipal waste management in Sicily: practice and challenges. Waste Management, n. 28, p.1201-1208, 2008.

MINGHUA, Z.; XIUMIN, F.; ROVETTA, A.; QICHANG, H.; VICENTINI, F.; BINGKAI, L.; GIUSTI, A.; YI, L.. Municipal solid waste management in Pudong new area, China. Waste Management. n.29, p.1227-1233, 2009.

MOEDINGER, F.; RADA, E. C.; RAGAZZI, M.; IONESCU, G.; RABONI, M.; TORRETTA, V.. Municipal solid waste treatment by integrated solutions: energy and environmental balances. Energy Procedia, n.50, p. 1037-1044, 2014.

OLIVEIRA, L. N.; ROSA, L. P.. Brazilian waste potential: energy, environmental, social and economic benefits. Energy Policy, v.31, p.1481-1491, 2003.

PIRES, A.; CHANG, N.; MARTINHO, G.. An AHP-based fuzzy interval TOPSIS assessment for sustainable expansion of the solid waste management system in Setúbal Peninsula, Portugal. Resources,

Comservation and Recycling, n. 56, p.7-21, 2011.

RAVINDRA, K.; KAUR, K.; MOR, S.. System analysis of municipal solid waste management in Chandigarh and minimization practices for cleaner emissions. Journal of Cleaner production, n.89, p.251-256, 2015.

ROCA, E.; HERVA, M.; NETO, B.. Environmental assessement of the integrated municipal solid watse management system in Porto (Portugal). Journal of Cleaner Production. n 70, p.183-193, 2014.

ROBBA, M.; MINCIARDI, R.; PAOLUCCI, M.; SACILE, R.. Multi-objective optimization of solid waste flows: environmentallu sustainable strategies for municipalities, Waste Management, n. 28, p.2202-2212, 2008.

ROGERS, D. S.; TIBBEN-LEMBKE, R. S.. Going backwards: reverse logistics trends and practices. Pittsburg: Reverse Logistics Executive Council, , 1998.

SEMIAO, V.; MAGRINHO, A.; DIDELET, F.. Municipal solid waste disposal in Portugal. Waste Management, n. 26, p.1477-1489, 2006. 
SMA/CEA. Guia pedagógico do lixo. 6 ed. São Paulo: Secretaria do Meio Ambiente e Coordenadoria de Educação Ambiental, 2011.

SRHU/MMA. Guia de elaboração dos planos de gestão de resíduos sólidos. Brasília: Secretaria de Recursos Hídricos e Ambiente Urbano, Ministério do Meio Ambiente, 2011.

SU, J.; XI, B. D.; LIU, H. L.; WARITH, M. A.. An inexact multi-objective dynamic model and its application in China for the management of municipal solid waste. Waste Management, n. 28, p.2532-2541, 2008.

SU, J.; XI, B. D.; HUANG, G. H.; QIN, X. S.; JIANG, Y. H.; HUO, S. L.; JI, D. F.; YAO, B.. An integrated optimization approach and multi-criteria decision analysis for supporting the waste-management system of the city of Beijing, China. Engineering Application of Artificial Intelligence, n. 23, p.620-631, 2010.

TALYAN, V.; DAHIYA, R. P.; SREEKRISHNAN, T. R.. State of municipal solid waste management in Delhi, the capital of India. Waste Management. n.28, p.1276-1287, 2008.

THIERRY, M.; SALOMON, M.; VAN NUNEN, J. A. E. E.; VANWASSENHOVE, L. N.. Strategic Issues in Product Recovery Management. California Management Review. v.37, p.114-135, 1995.

WANG, Z.; SONG, Q.; LI, J.. Environmental performance of municipal solid waste strategies based on LCA method: a case study of Macau. Journal of Cleaner Production. n.57, p.92-100, 2013.

WARITH, M. A.; MOHAREB, A. K.; DIAZ, R.. Modelling greenhouse gas emission for municipal solid waste management strategies in Ottawa, Ontario, Canada. Resources, Conservation and Recycling, n.52, p. 1241-1251, 2008.

YEOMANS, J. S.. Solid waste planning under uncertainty using evolutionary simulation-optimization. SocioEconomic Planning Sciences, n.41, p.38-60, 2007.

ZHANG, D. Q.; TAN, S. K.; GERSBERG, R. M.. Municipal solid waste management in China: status, problems and challenges. Journal of Environmental Management, v.91, p.1623-1633, 2010

ZHANG, Y.; HUANG, G. H.; HE, L.. A multi-echelon supply chain model for municipal solid waste management system. Waste Management, n.34, p.553-561, 2014.

ZHANG, X.; HUANG, G.. Optimization of environmental management strategies through a dynamic stochastic possibilistic multiobjective program. Journal of Hazardous Material. n.246-247, p.257-266, 2013.

ZHEN-SHAN, L.; LEI, Y.; XIAO-YAN, Q.; YU-MEI, S.. Municipal solid waste management in Beijing City. Waste Management, n.29, p.2596-2599, 2009. 